\title{
New Formulations Loading Caspofungin for Topical Therapy of Vulvovaginal Candidiasis
}

\author{
Noelia Pérez-González ${ }^{1}$, Nuria Bozal-de Febrer ${ }^{2}{ }^{(0)}$, Ana C. Calpena-Campmany ${ }^{3,4}{ }^{\circledR}$, Anna Nardi-Ricart ${ }^{1}(\mathbb{D}$, \\ María J. Rodríguez-Lagunas ${ }^{5,6}{ }^{\circledR}$, José A. Morales-Molina ${ }^{7}$, José L. Soriano-Ruiz ${ }^{1}{ }^{\circledR}$, \\ Francisco Fernández-Campos $8, *(1)$ and Beatriz Clares-Naveros $1,4,9$ (i)
}

Citation: Pérez-González, N.; Bozal-de Febrer, N.; Calpena-Campmany, A.C.; Nardi-Ricart, A.; Rodríguez-Lagunas, M.J.; Morales-Molina, J.A.; Soriano-Ruiz, J.L.; Fernández-Campos, F.;

Clares-Naveros, B. New Formulations Loading Caspofungin for Topical Therapy of Vulvovaginal Candidiasis. Gels 2021, 7, 259. https://doi.org/ $10.3390 /$ gels7040259

Academic Editors: Yi Cao and Maria Valentina Dinu

Received: 3 November 2021

Accepted: 7 December 2021

Published: 12 December 2021

Publisher's Note: MDPI stays neutral with regard to jurisdictional claims in published maps and institutional affiliations.

Copyright: (c) 2021 by the authors. Licensee MDPI, Basel, Switzerland This article is an open access article distributed under the terms and conditions of the Creative Commons Attribution (CC BY) license (https:// creativecommons.org/licenses/by/ $4.0 /)$
1 Department of Pharmacy and Pharmaceutical Technology, Faculty of Pharmacy, Campus of Cartuja University of Granada, 18071 Granada, Spain; noeliaperez93@correo.ugr.es (N.P.-G.); annanardi@ub.edu (A.N.-R.); jlsoriano@correo.ugr.es (J.L.S.-R.); beatrizclares@ugr.es (B.C.-N.)

2 Department of Biology, Healthcare and the Environment, Faculty of Pharmacy and Food Sciences, University of Barcelona, 27-31 Joan XXIII Ave., 08028 Barcelona, Spain; nuriabozaldefebrer@ub.edu

3 Department of Pharmacy and Pharmaceutical Technology and Physical Chemistry, Faculty of Pharmacy and Food Sciences, University of Barcelona, 27-31 Joan XXIII Ave., 08028 Barcelona, Spain; anacalpena@ub.edu

4 Institute of Nanoscience and Nanotechnology (IN2UB), University of Barcelona, 08028 Barcelona, Spain

5 Department of Biochemistry and Physiology, Faculty of Pharmacy and Food Sciences, University of Barcelona, 08028 Barcelona, Spain; mjrodriguez@ub.edu

6 Institute of Biomedicine, University of Barcelona, 08028 Barcelona, Spain

7 Department of Pharmacy, Torrecárdenas University Hospital, s/n Hermandad de Donantes de Sangre St., 04009 Almeria, Spain; joseantonio.morales@ephpo.es

8 Reig-Jofre Laboratories, Av. de les Flors s/n, 08970 Sant Joan Despi, Spain

9 Biosanitary Institute of Granada (ibs.GRANADA), 18012 Granada, Spain

* Correspondence: ffernandez@reigjofre.com

Abstract: Vulvovaginal candidiasis (VVC) poses a significant problem worldwide affecting women from all strata of society. It is manifested as changes in vaginal discharge, irritation, itching and stinging sensation. Although most patients respond to topical treatment, there is still a need for increase the therapeutic arsenal due to resistances to anti-infective agents. The present study was designed to develop and characterize three hydrogels of chitosan (CTS), Poloxamer 407 (P407) and a combination of both containing $2 \%$ caspofungin (CSP) for the vaginal treatment of VVC. CTS was used by its mucoadhesive properties and P407 was used to exploit potential advantages related to increasing drug concentration in order to provide a local effect. The formulations were physically, mechanically and morphologically characterized. Drug release profile and ex vivo vaginal permeation studies were performed. Antifungal efficacy against different strains of Candida spp. was also evaluated. In addition, tolerance of formulations was studied by histological analysis. Results confirmed that CSP hydrogels could be proposed as promising candidates for the treatment of VVC.

Keywords: vulvovaginal candidiasis; antifungal therapy; caspofungin; vaginal mucosal delivery; mucoadhesive hydrogel; thermoreversible hydrogel

\section{Introduction}

Vulvovaginal candidiasis (VVC) is a health problem that affects approximately 70-75\% of women worldwide at least once during their lifetime [1,2]. It has been estimated that about $50 \%$ of women will suffer VVC again and $8 \%$ will develop chronic VVC [3]. The symptoms include changes in vaginal discharge, irritation and itching sensation, stinging, burning sensation inside and/or outside the vagina, pain during urination and discomfort during sexual intercourse. Other symptoms include scratching lesions, swelling and vulvar redness [4]. Candidiasis is commonly caused by Candida spp. The predominant species are C. albicans, followed by C. glabrata, C. tropicalis, C. krusei and C. parapsilosis [5]. VVC is estimated to be the second most common cause of vaginitis after bacterial vaginosis. $C$. albicans accounts for $85-90 \%$ of cases [6]. 
On the other hand, infections of the genitourinary system are the second reason for consultation during and after the severe acute respiratory syndrome coronavirus 2 (SARS-CoV-2) pandemic. Without epidemiological studies to confirm this, a considerable portion of health care has been motivated by vulvovaginal symptoms compatible with vulvovaginitis due to Candida spp. Changes in habits, stress, the use of broad-spectrum antibiotics or dexamethasone [7], prolonged stays in the intensive care units, or catheters may be important factors that cause patients with COVID-19 to develop these vaginal infections through the alteration of the microbiological balance of the area [8]. In addition, COVID-19 disease, caused by SARS-CoV-2, may increase systemic fungal co-infections associated with COVID-19. Patients with COVID-19, especially those who are affected severely or immunocompromised are more susceptible to develop invasive mycoses [9].

Although most patients with VVC respond to topical treatment, mortality rates associated with invasive fungal infections are really high, and there is a growing concern about resistance to anti-infective agents $[10,11]$. Fortunately, the arsenal of antifungal agents is continuously improved and a new antifungal drug family is being developed: echinocandins [12-14]. Among this family caspofungin (CSP) is a semi-synthetic water soluble lipopeptide obtained from Glarea lozoyensis as a fermentation product. The mechanism of action consists of blocking the synthesis of an essential component of the cell wall of numerous fungal species, $\beta$ (1,3)-D-glucan. CSP is presented as a lyophilized powder in its acetate form. This drug is only available for hospital use and it is administered intravenously [15-18].

It is of outmost importance for drug administration through vaginal area to take into account the anatomy of this especial cavity as well as its secretions, as the resulting fluids can alter both the retention of the formulation and the release of the drug [19]. To overcome these problems, formulations aimed to provide spatial and temporal control of drug delivery have been designed by providing coverage of the affected areas without elimination, as well as being compatible with aqueous environments. These formulations are hydrogels [20]. Different hydrogels as drug delivery system against VVC have been used focusing on the effective therapeutic response at the vaginal mucosa. A review of the literature shows that most of these formulations are hydrogels loaded with classical antifungal drugs such as amphotericin B, miconazole or clotrimazole [21-25]. However, other authors have opted to incorporate into their formulations alkannin, diphenyl diselenide, anise or terbinafine, among others [26-29]. There are not previous studies reporting the delivery of CSP because is the first time it has been applied topically in vaginal mucosa. Only a topical study of eye drops has been found in the literature [30].

It is well-known that hydrogels are three-dimensional polymeric networks containing large amounts of water in their structure [31]. Water-soluble polymers have the ability to adhere to mucosal tissues. These mucoadhesive properties are related to those charged polymers with a higher molecular weight, which possess greater ability to adhere to tissues [32]. Chitosan (CTS) is a cationic polysaccharide that exhibits antimicrobial activity. It is also characterized by mucoadhesive properties [33-35]. CTS has been chosen in this work because of its biocompatibility, biodegradability, ability to form gels in situ with negatively charged macromolecules and for its mucoadhesive, antimicrobial and antifungal properties. The cationic nature of CTS confers a sol-gel transition at $\mathrm{pH} 6.5$, when the medium changes from acidic to neutral [36,37]. In its context, poloxamer 407 (P407) is a hydrophilic non-ionic surfactant belonging to the poloxamers copolymers family, which are known for being thermoreversible [38]. Both CTS and P407 have been widely used as delivery systems for the release of different drugs for vaginal administration [39-43].

In recent years, polymer combination designs have been developed to give them multifunctionality. Natural polymers, such as CTS, ensure minimally invasive gels in the human body, while synthetic polymers, such as P407, produce gels with high mechanical resistance. The advantage of joining both polymers would let us to obtain a hydrogel with optimal biocompatible and biodegradable nature, high-water content, high responsiveness and permeability, and then obtain an improved therapeutic effect [44]. Both polymers are 
linked by non-covalent interactions between the amino groups of CTS and the ethylene oxide units of P407 to form a high-strength physical [45]. The combination of these polymers has also been used for drug delivery, including vaginal administration [46-49].

Thus, the main objective of this study is the development of a topical delivery system for the vehiculization of CSP. The vaginal topical use of CSP has never been reported. For this general purpose, three formulations in form of hydrogels of CTS, P407 and the combination of both have been investigated for the treatment of VVC. The specific goals of this research are: (i) the detailed physicochemical characterization of CSP hydrogels for topical application, (ii) the in vitro release and ex vivo permeation studies through vaginal tissues, (iii) the in vitro studies of antifungal activity and, (iv) the histological evaluation of the effect of these formulations.

\section{Results and Discussion}

\subsection{Physical Characterization of Caspofungin Hydrogels}

\subsection{1. $\mathrm{pH}$ Evaluation}

The $\mathrm{pH}$ values for CSP-CTS, CSP-P407 and CSP-CTS/P407 hydrogels were $4.58 \pm 0.05$, $6.27 \pm 0.03$ and $4.24 \pm 0.05$, respectively. None of these values changed after three monthstorage period at $4 \pm 1.00^{\circ} \mathrm{C}$. When the formulations were mixed with simulated vaginal fluid (SVF), the $\mathrm{pH}$ of CSP-CTS and CSP-CTS/P407 remained unaltered, while the $\mathrm{pH}$ of CSP-P407 decreased to $4.58 \pm 0.10$.

Although the $\mathrm{pH}$ of the vagina is around 4.5 , it can be affected when an infection occurs, then it could reach up to $7[10,50]$. In the present study, the $\mathrm{pH}$ of the formulations was found to be within the vaginal $\mathrm{pH}$ conditions.

\subsubsection{Morphological Studies}

In order to characterize the microstructural architecture of samples a Scanning Electron Microscopy (SEM) analysis was performed. Figure 1A shows a uniform network sheet of CSP-CTS hydrogel without pores or cracks in its fibrous structure. As a result, a homogeneous and well-controlled final morphology has been obtained. The figure corresponding with the sample CSP-P407 hydrogel (Figure 1B) illustrates a highly porous structure typical of P407. Figure 1C shows a highly porous network with more distinct pores than CSP-P407 network, resulting in better interconnection between CTS and P407 [51]. Probably, for CSPP407 hydrogel micelles contacted mutually similarly to the increase in viscosity. Instead for the CSP-CTS/P407 hydrogel chitosan is sandwiched between micelles [52].

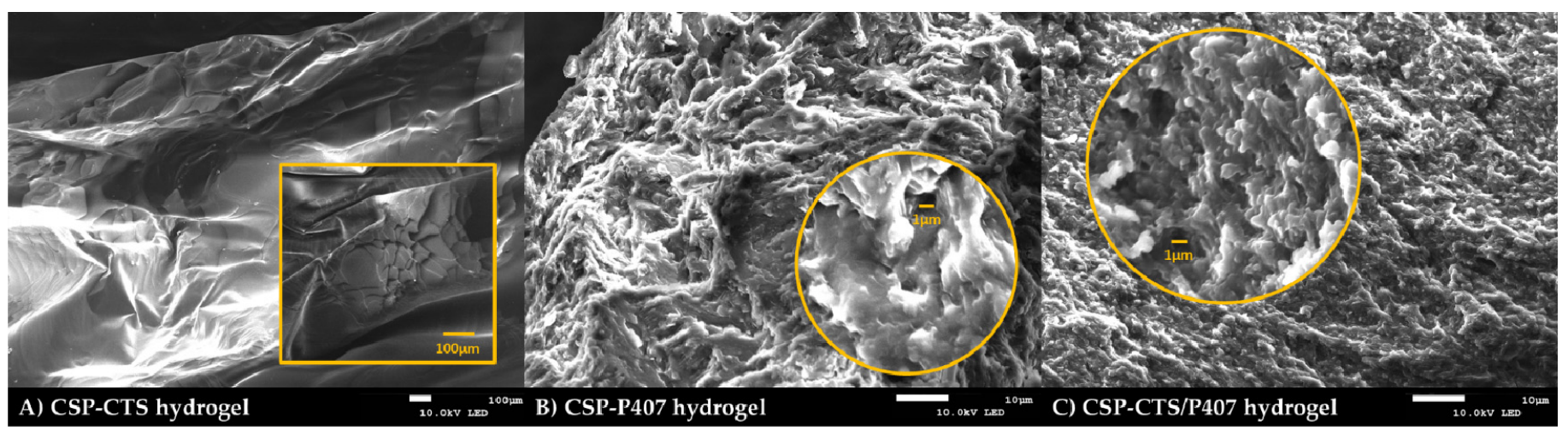

Figure 1. Scanning Electron Microscope micrographs images obtained for: (A) CSP-CTS hydrogel at $50 \times($ magnification $850 \times)$; (B) CSP-P407 hydrogel at 1200× (magnification 4300×); and (C) CSP-CTS/P407 hydrogel at 1200× (magnification 4500×).

Finally, the SEM image confirms that the drug has been correctly incorporated into the hydrogels because no drug crystals were observed adhering to the surface. 


\subsubsection{Surface Electrical Properties}

The surface charge of the formulation is a parameter that informs about its stability, clearance, as well as its solubility and drug distribution [53]. As shown in Table 1, the zeta potential (ZP) values were $80.36 \pm 4.72,11.14 \pm 1.62$ and $49.76 \pm 3.22 \mathrm{mV}$ for CTS, P407 and CTS/P407 hydrogels, respectively. Values for CSP loaded hydrogels were $74.00 \pm 4.19$, $9.94 \pm 0.74$ and $40.51 \pm 3.87 \mathrm{mV}$ for CSP-CTS, CSP-P407 and CSP-CTS/P407 hydrogels, respectively. No significant changes $(p<0.05)$ in ZP values were observed when CSP was incorporated into the formulations, indicating that it was uniformly distributed in the system without precipitation.

Table 1. Zeta potential data of unloaded and loaded formulations. Zeta potential data represent the mean \pm SD of nine replicates.

\begin{tabular}{ccc}
\hline & \multicolumn{2}{c}{ Zeta Potential Values (mV) } \\
\cline { 2 - 3 } & CSP-Loaded & CSP-Unloaded \\
\hline CTS hydrogel & $80.36 \pm 4.72$ & $74.00 \pm 4.19$ \\
P407 hydrogel & $11.14 \pm 1.62$ & $9.94 \pm 0.74$ \\
CTS/P407 hydrogel & $49.76 \pm 3.22$ & $40.51 \pm 3.87$ \\
\hline
\end{tabular}

\subsubsection{Rheological Behavior}

The rheological characteristics of formulations play an important role in physical stability, sensorial characteristics, spreadness and dosing behavior. All these properties are related with the application characteristics and are crucial attributes for the development of topical drug products [54-56]. Sample readings were taken at 4,25 and $37{ }^{\circ} \mathrm{C}$ in order to reproduce the behavior after storage in the refrigerator or at room temperature, and after application in the vaginal cavity.

Under rotational testing, CSP-CTS and CTS/P407 hydrogels presented a non-newtonian behavior (Table 2), adjusting to a shear thinning (pseudoplastic) profile, being the Cross equation the model that best fitted experimental data. Moreover, the flow curves showed an apparent thixotropic behavior in both systems as the rheograms displayed a hysteresis loop. These rheological characteristics are desirable for topical application, allowing the formation of a stable and consistent film covering the application area that allows the diffusion of the drug through the matrix $[54,57,58]$. This can also be an interesting feature because it improves syringeability properties and thus facilitate vaginal administration with the cannula.

The results of Table 2 also reveal that CSP-CTS hydrogel presented at $50 \mathrm{~s}^{-1}$ higher viscosity values than CSP-CTS/P407 hydrogel, $2237 \pm 13.40 \mathrm{mPa} \cdot \mathrm{s}$ and $1868 \pm 14.11 \mathrm{mPa} \cdot \mathrm{s}$ at $4{ }^{\circ} \mathrm{C}$, respectively. For both formulations, the increase of temperature involved similar decrease in the viscosity under rotational testing conditions. However, the CSP-P407 hydrogel corresponds to a typical poloxamer-based thermoreversible gel which has the characteristic of being liquid and syringeable at low temperatures and gel at the body temperature [59]. Therefore, the CSP-P407 hydrogel viscosity increased from $16.45 \pm 0.60 \mathrm{mPa} \cdot \mathrm{s}$ (SOL structure at $4{ }^{\circ} \mathrm{C}$ ) to $70.73 \pm 2.02 \mathrm{mPa} \cdot \mathrm{s}\left(\mathrm{GEL}\right.$ structure at $37^{\circ} \mathrm{C}$ ). These viscosity values were much lower than those obtained for gels CSP-CTS hydrogel and CSP-CTS/P407 hydrogel, both with the same quantity of CTS. In parallel, the CSP-P407 hydrogel flow curve presented a nearly newtonian behavior at $4{ }^{\circ} \mathrm{C}$ and a shear thinning character at $37^{\circ} \mathrm{C}$, according to the change of the structure of the system.

Although the rotational testing did not detect the thermogelling phenomenon of the poloxamer included in the combination of CSP-CTS/P407 system, the temperature sweep under oscillatory testing did give evidence of this process. The results of the temperature sweep test performed to investigate the in-situ poloxamer gelling in the case of CSP-P407 hydrogel and CSP-CTS/P407 hydrogel are depicted in Figure 2. According to the CSP-P407 hydrogel graph (Figure 2A), the $T_{\text {SOL-GEL }}$ (where $G^{\prime}=G^{\prime \prime}$ ) was about $25^{\circ} \mathrm{C}$. This is the temperature at which the sample exhibits a switch from a prevalently viscous behavior 
$\left(G^{\prime \prime}>G^{\prime}\right)$ to a prevalently elastic one $\left(G^{\prime}>G^{\prime \prime}\right)$. This interesting gelation process results in an increase in the residence time avoiding the rapid gel elimination [59].

Table 2. Results of the rheological rotational testing of the formulations CSP-CTS, CSP-P407 and CSP-CTS/P407 hydrogels.

\begin{tabular}{|c|c|c|c|c|c|}
\hline \multirow{2}{*}{ Samples } & \multirow{2}{*}{$\begin{array}{c}\text { Temperature } \\
\left({ }^{\circ} \mathrm{C}\right)\end{array}$} & \multicolumn{2}{|c|}{ Rheological Behavior and Model } & \multirow{2}{*}{$\begin{array}{c}\text { Viscosity at } 50 \mathrm{~s}^{-1} \\
(\mathrm{mPa} \cdot \mathrm{s})\end{array}$} & \multirow{2}{*}{$\begin{array}{l}\text { Apparent } \\
\text { Thixotropy }\end{array}$} \\
\hline & & Stretch Ramp-Up & Stretch Ramp-Down & & \\
\hline \multirow{3}{*}{$\begin{array}{l}\text { CSP-CTS } \\
\text { hydrogel }\end{array}$} & 4 & $\begin{array}{c}\text { Pseudoplastic } \\
\text { (Cross, } r=0.9998)\end{array}$ & $\begin{array}{l}\text { Pseudoplastic } \\
\text { (Cross, } r=1 \text { ) }\end{array}$ & $2237 \pm 13.40$ & Presence \\
\hline & 25 & $\begin{array}{c}\text { Pseudoplastic } \\
\text { (Cross, } r=0.9999)\end{array}$ & $\begin{array}{l}\text { Pseudoplastic } \\
(\text { Cross, } r=1)\end{array}$ & $1645 \pm 11.87$ & Presence \\
\hline & 37 & $\begin{array}{c}\text { Pseudoplastic } \\
(\text { Cross, } \mathrm{r}=0.9999)\end{array}$ & $\begin{array}{l}\text { Pseudoplastic } \\
(\text { Cross, } \mathrm{r}=1)\end{array}$ & $1291 \pm 7.08$ & Presence \\
\hline \multirow{3}{*}{$\begin{array}{l}\text { CSP-P407 } \\
\text { hydrogel }\end{array}$} & 4 & $\begin{array}{c}\text { Pseudoplastic } \\
\text { (Cross, } r=0.9997)\end{array}$ & $\begin{array}{c}\text { Newtonian } \\
\text { (Newton, } \mathrm{r}=0.9999)\end{array}$ & $16.45 \pm 0.60$ & Absence \\
\hline & 25 & Irregular flow & Irregular flow & $73.94 \pm 6.09$ & Presence \\
\hline & 37 & $\begin{array}{c}\text { Pseudoplastic } \\
\text { (Cross, } \mathrm{r}=0.9989\end{array}$ & $\begin{array}{c}\text { Pseudoplastic } \\
\text { (Cross, } r=0.9974)\end{array}$ & $70.73 \pm 2.02$ & Presence \\
\hline \multirow{3}{*}{$\begin{array}{l}\text { CSP-CTS/P407 } \\
\text { hydrogel }\end{array}$} & 4 & $\begin{array}{c}\text { Pseudoplastic } \\
\text { (Cross, } r=0.9997)\end{array}$ & $\begin{array}{l}\text { Pseudoplastic } \\
(\text { Cross, } \mathrm{r}=1)\end{array}$ & $1868 \pm 14.11$ & Presence \\
\hline & 25 & $\begin{array}{c}\text { Pseudoplastic } \\
\text { (Cross, } r=0.9998)\end{array}$ & $\begin{array}{l}\text { Pseudoplastic } \\
(\text { Cross, } r=1)\end{array}$ & $1425 \pm 12.88$ & Presence \\
\hline & 37 & $\begin{array}{c}\text { Pseudoplastic } \\
\text { (Cross, } r=0.9997)\end{array}$ & $\begin{array}{l}\text { Pseudoplastic } \\
(\text { Cross, } r=1)\end{array}$ & $1009 \pm 5.51$ & Presence \\
\hline
\end{tabular}

Regarding the CSP-CTS/P407 hydrogel graph (Figure 2B), the crossover corresponding to the $\mathrm{T}_{\mathrm{SOL}-\mathrm{GEL}}$ took place earlier, at $19.5^{\circ} \mathrm{C}$ and compared to the CSP-P407 hydrogel graph, at low temperatures the values of both $G^{\prime}$ and $G^{\prime \prime}$ moduli were much higher. It has been indicated that using a $20 \%(w / v)$ solution of poloxamer, with the addition of chitosan $(1.5 \% w / v)$ a syringeable, thermosensitive and mucoadhesive gel could be obtained [60]. However, in the case of CSP-CTS/P407 hydrogel, the addition of CTS modifies the properties of the system. CTS interacts with $\mathrm{P} 407$ through its polyethylene oxide chains, increasing the number of hydrophilic chains and therefore the thickness of the micellar crown. Due to this interaction, the apparent viscosity could increase and the temperature $\mathrm{T}_{\text {SOL-GEL }}$ could decrease $[52,61]$.

\subsubsection{Spreadability Test}

Spreadability properties of samples are important parameters to evaluate in topical forms because can influence both the packaging process and the uniformity of dose and application, and therefore the therapeutic efficacy $[57,62]$. The data obtained in the test are presented in Figure 3. It can be easily observed that the developed hydrogels exhibit higher extensibility values than the reference sample. CSP-CTS/P407 hydrogel possess the highest area, $28.27 \mathrm{~cm}^{2}$, followed by CSP-CTS and P407-CPS hydrogels, with areas of 20.44 and $16.63 \mathrm{~cm}^{2}$, respectively. The reference sample showed an area of $10.51 \mathrm{~cm}^{2}$.

In terms of application, CSP-CTS/P407 hydrogel facilitates application on the vaginal mucosal, an anatomical area where application is especially difficult.

Promisingly, CSP-CTS/P407 hydrogel can be a potential formulation for the treatment of vaginal infection. Due to its thermo-sensitive properties, the hydrogel in the SOL state penetrate to the infection sites in deep vaginal rugae, in contrast in GEL state will provide improved mucosal adhesion and prolonged drug retention (Figure 4). 

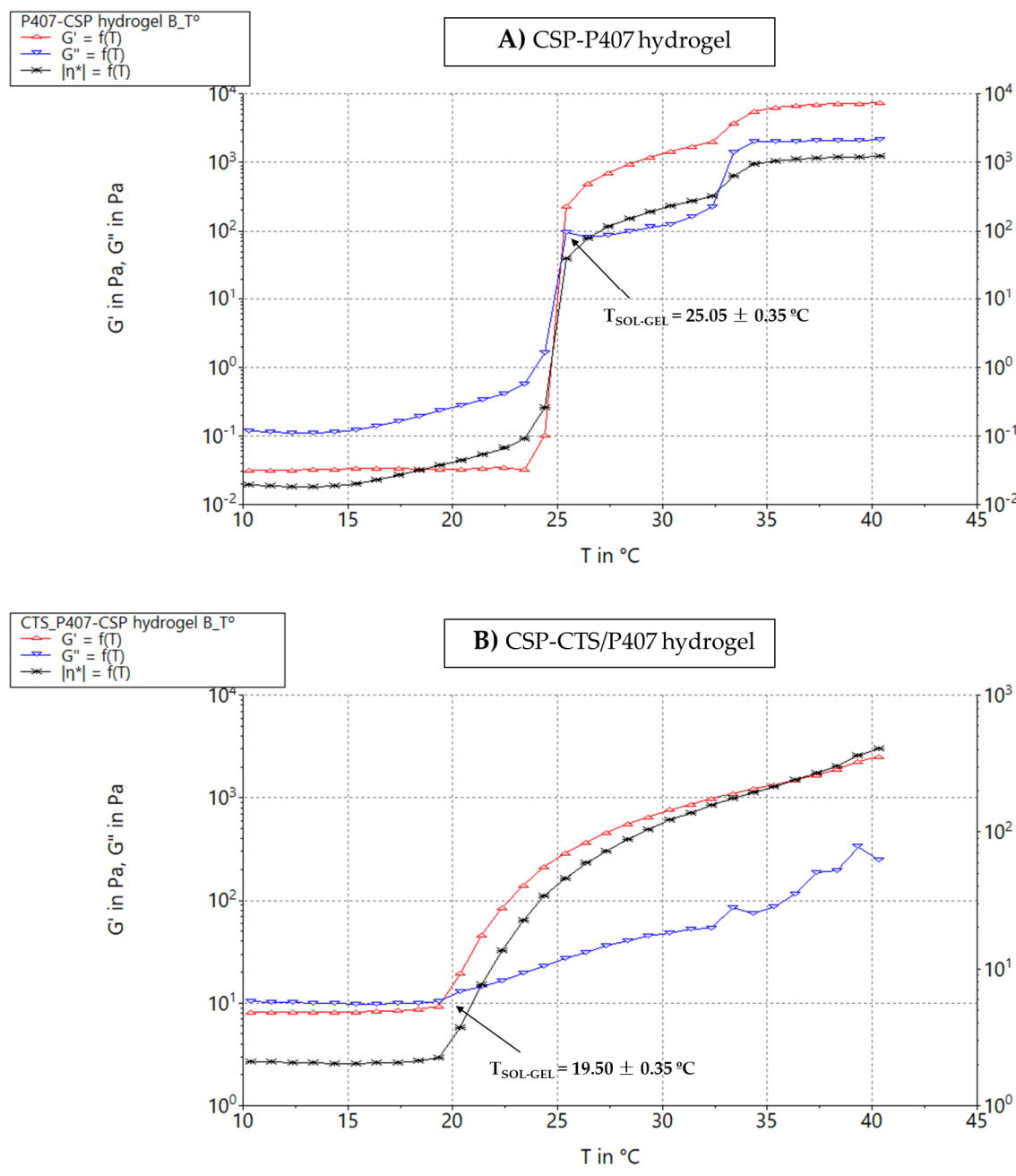

Figure 2. SOL-GEL Temperature Transition: (A) CSP-P407 hydrogel; and (B) CSP-CTS/P407 hydrogel.

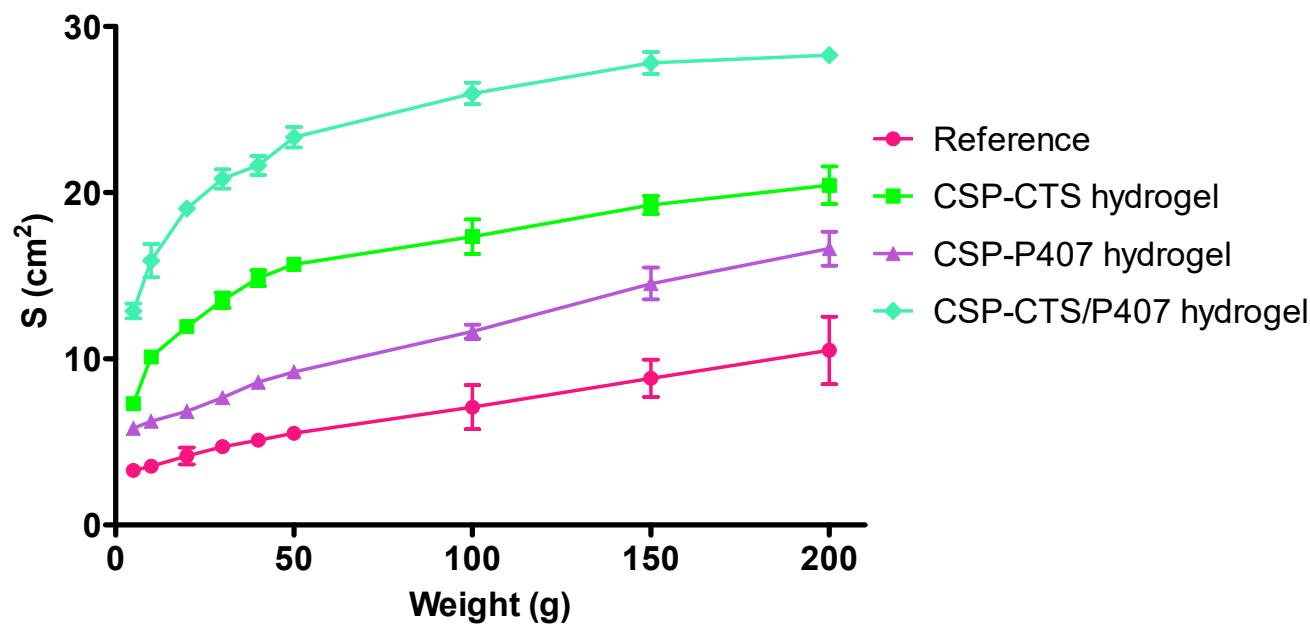

Figure 3. Spreading area $\left(\mathrm{S}, \mathrm{cm}^{2}\right)$ as a function of the applied mass $(\mathrm{g})$ at $37{ }^{\circ} \mathrm{C}$ of reference and CSP-CTS, CSP-P407 and CSP-CTS/P407 hydrogels. Each value represents the mean \pm SD $(n=3)$. 


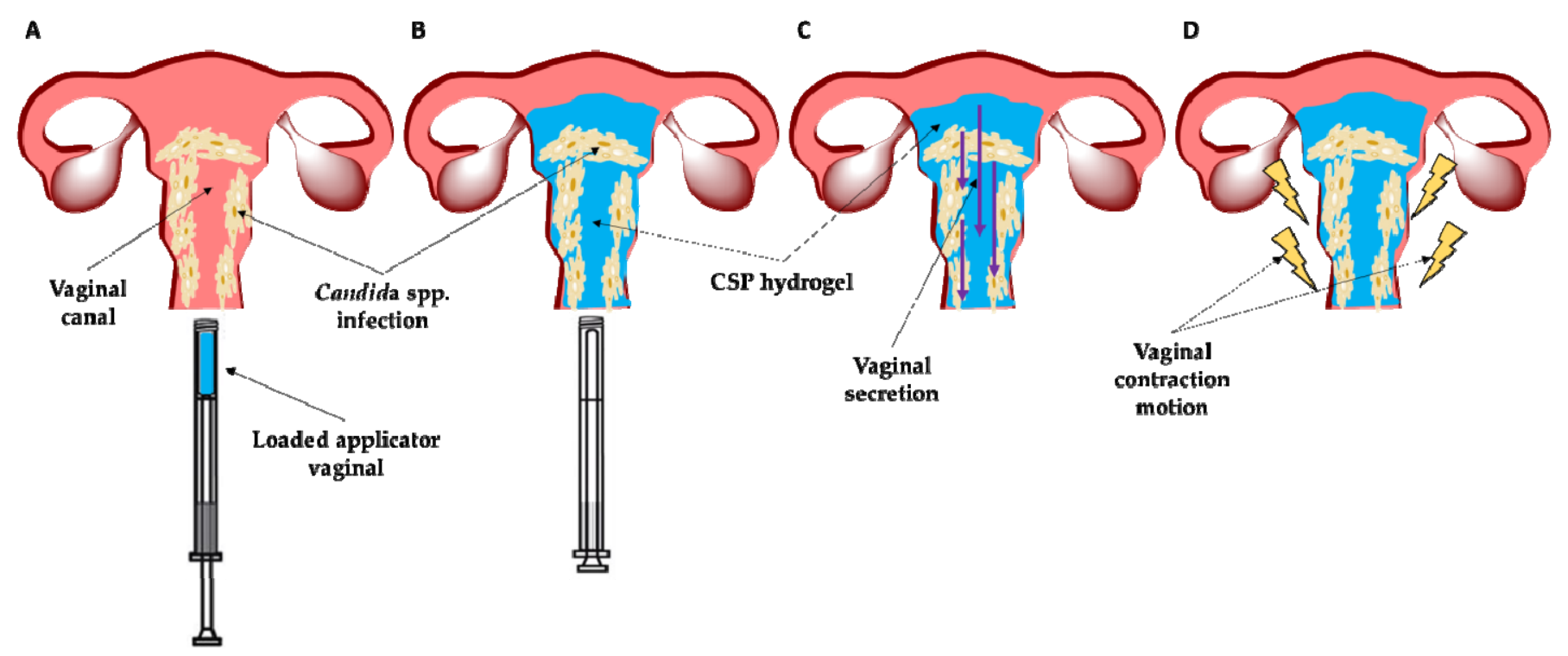

Figure 4. Schematic illustration of the mechanism of hydrogel application: (A) Administration into the vaginal cavity of the formulation through an applicator; (B) Expansion of the hydrogel through the vaginal cavity covering the infection focus; (C) Resistance of the hydrogel to vaginal secretion; and (D) Resistance of the hydrogel to vaginal contraction movement.

\subsubsection{Extrudability Study}

The results of extrudability can be observed in Table 3. It should be taken into consideration that vaginal applicators are hollow tubes whose lumen is much bigger than that of a syringe. Therefore, it would be convenient for the formulation to be expelled by exerting the minimal force as possible [57].

Table 3. Extrudability $\left(\mathrm{g} / \mathrm{cm}^{2}\right)$ behavior at $4{ }^{\circ} \mathrm{C}$ of reference and CSP hydrogel. Each value represents the mean $\pm \operatorname{SD}(n=3)$.

\begin{tabular}{cc}
\hline & Extrudability $\left(\mathbf{g} / \mathbf{c m}^{2}\right)$ \\
\hline Reference & $8.05 \pm 0.29 *$ \\
CSP-CTS hydrogel & $4.52 \pm 0.43^{*}$ \\
CSP-P407 hydrogel & $0.07 \pm 0.01^{*}$ \\
CTS/P407 hydrogel & $1.83 \pm 0.09 *$ \\
\hline
\end{tabular}

${ }^{*}$ Represent significant differences $(p<0.001)$.

As might be expected, CSP-P407 hydrogel is the sample that extrudes most easily, but this could cause administration problems due to spillage. The reference sample has the highest extrusion value, indicating that it requires the maximum force to be extruded from the applicator. In contrast, CSP-CTS/P407 hydrogel shows better extrudability than CSP-CTS hydrogel. Based on these results, the hydrogel formed by the combination of both polymers shows the best extrudability properties.

\subsubsection{Evaluation of Mucoadhesion Properties}

The mucoadhesive properties of vaginal formulations are essential due to the selfcleaning of the vagina. When compared the $\mathrm{ZP}$ data of the mucin solution with the $\mathrm{ZP}$ data obtained for the hydrogel-mucin mixtures, it was observed that the $\mathrm{ZP}$ value of the mucin dispersion, $-12.86 \pm 0.70 \mathrm{mV}$, changed when mixed it with the samples as shown in Figure 5. This change in value would be due to the interactions of the negative groups, such as carboxylate $\left(\mathrm{COO}^{-}\right)$and sulfonate $\left(\mathrm{SO}_{3}{ }^{-}\right)$of mucin with the positive groups of the polymers [63]. A polymer with mucoadhesive properties is able to neutralize the mucin charge [64]. The hydrogel that showed the maximum displacement was CSP-CTS, $58.47 \pm 3.46 \mathrm{mV}$, confirming the mucoadhesive properties attributed to CTS due to its 
cationic nature [65], followed by CSP-CTS/P407, the reference and CSP-P407 with ZP values of $35.59 \pm 3.15,-7.92 \pm 0.98$ and $-3.89 \pm 0.36 \mathrm{mV}$, respectively.

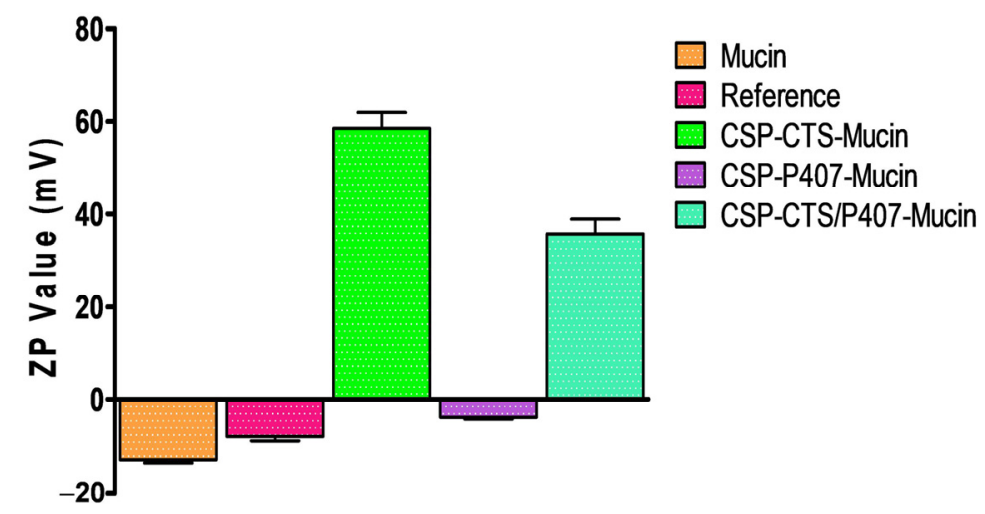

Figure 5. Zeta potential of mucin solution, CSP-CTS-Mucin solution, CSP-P407-Mucin solution and CSP-CTS/P407-Mucin solution Results are expressed as mean values $\pm \operatorname{SD}(n=9)$.

\subsection{In Vitro Release and Kinetic Evaluation}

The release profiles of the CSP hydrogels can be observed in Figure 6. After $8 \mathrm{~h}$, the highest cumulative drug release was registered for CSP-P407 hydrogel. Its micellar properties provide a system with excellent solubility [66]; followed by CSP-CTS/P407 and CSP-CTS.

The results of model fitting showed different release profiles for samples. CSP-CTS and CSP-CTS/P407 were adjusted to a Fickian kinetic model while CSP-P407 was adjusted to a sigmoidal model. Based on each equation, the release rates for CSP-CTS, CSP-P407, and CSP-CTS/P407 were $0.20 \mathrm{~h}^{-1}, 0.85 \mathrm{~h}$ and $0.65 \mathrm{~h}^{-1}$, respectively.

In order to compare the biopharmaceutical profile of all formulations, some amodelistic parameters (Figure 7) such as mean dissolution time (MDT), area under the curve (AUC) and efficiency (E) were calculated. CSP-CTS/P407 presents the lowest value of MDT, $1.7 \mathrm{~h}$, compared to 2.9 and $3.2 \mathrm{~h}$ of CSP-P407 and CSP-CTS, respectively. This fact indicates that among three formulations, one of them is able to release the drug most rapidly and it could provide better bioavailability in the tissue. The AUC results are statistically different, being lower for CSP-CTS, $2660.0 \mu \mathrm{g} / \mathrm{h}$, and higher for CSP-P407, 14,785.3 $\mu \mathrm{g} / \mathrm{h}$. Regarding the results of efficiency, CSP-CTS/P407 shows the highest value, 78.6\%. Probably, the interconnected porous morphology of CSP-CTS/P407 favors a better distribution of the drug within the hydrogel compared to the chains and agglomerated micelles of CSP-CTS and CSP-P407, respectively.

\subsection{Ex Vivo Permeation of Caspofungin through Vaginal Mucosa}

The vagina is a non-invasive route of administration in women that provides both a local and systemic effects. The aim of this study is to demonstrate that the therapeutic effect occurs locally in the vaginal mucosa. This is essential for fungal infections because fungi, mainly Candida spp., colonize the mucosal surface [67]. Therefore, a certain degree of permeation and retention of the drug in the tissue is necessary without reaching or exceeding systemic therapeutic levels, $C_{\min }=3.55 \mu \mathrm{g} / \mathrm{mL}$ and $C_{\max }=11.73 \mu \mathrm{g} / \mathrm{mL}$ [68-70]. Porcine and human vaginal mucosas are substantially similar. Hence, porcine vaginal mucosa was used for permeation studies [57]. There are not previous studies reporting permeation parameters of CSP through vaginal porcine mucosa. 
A

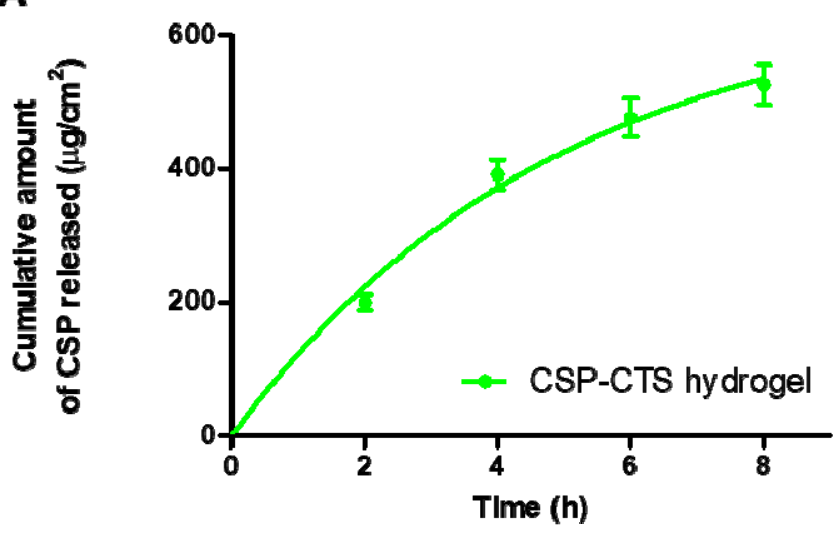

\begin{tabular}{lc}
\hline \multicolumn{2}{c}{ CSP-CTS hydrogel } \\
\hline \multicolumn{2}{c}{ One phase exponential association } \\
\hline Best-fit values \\
\hline Ymax $\left(\mu g / \mathrm{cm}^{2}\right)$ & 663.50 \\
$K(1 / \mathrm{h})$ & 0.20 \\
HalfLffe $(h)$ & 3.37 \\
\hline Std. Error & \\
\hline$Y \max$ & 80.74 \\
$K$ & 0.05 \\
$R^{2}$ & 0.91 \\
\hline
\end{tabular}

B
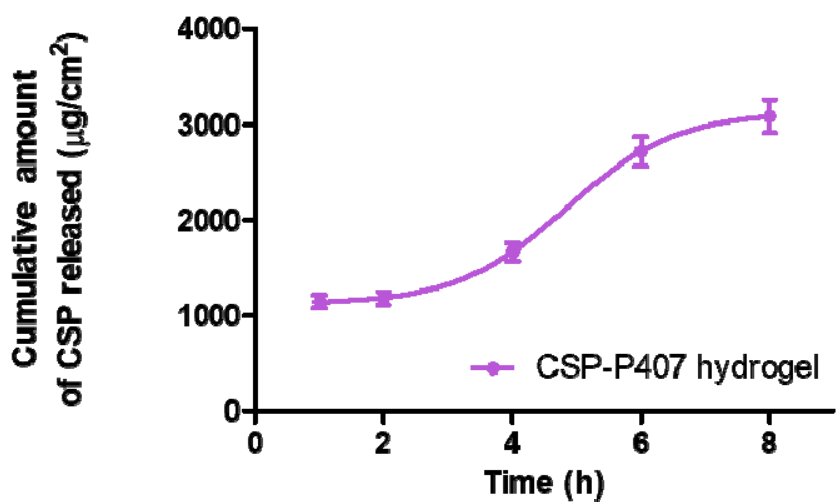

\begin{tabular}{lc}
\hline \multicolumn{2}{c}{ CSP-P407 hydrogel } \\
\hline \multicolumn{2}{c}{ Boltzmannsigmoidal } \\
\hline Best-fit values \\
\hline Bottom $(\mu \mathrm{g} / \mathrm{cm} 2)$ & 1122.00 \\
Top $\left(\mu \mathrm{g}^{\mathrm{cm}} \mathrm{)}\right)$ & 3132.00 \\
V50 $(\mathrm{h})$ & 4.84 \\
Slope $(\mathrm{h})$ & 0.85 \\
\hline Std. Error & \\
\hline Bottom & 105.80 \\
Top & 155.10 \\
V50 & 0.29 \\
Slope & 0.23 \\
$R^{2}$ & 0.95 \\
\hline
\end{tabular}

C
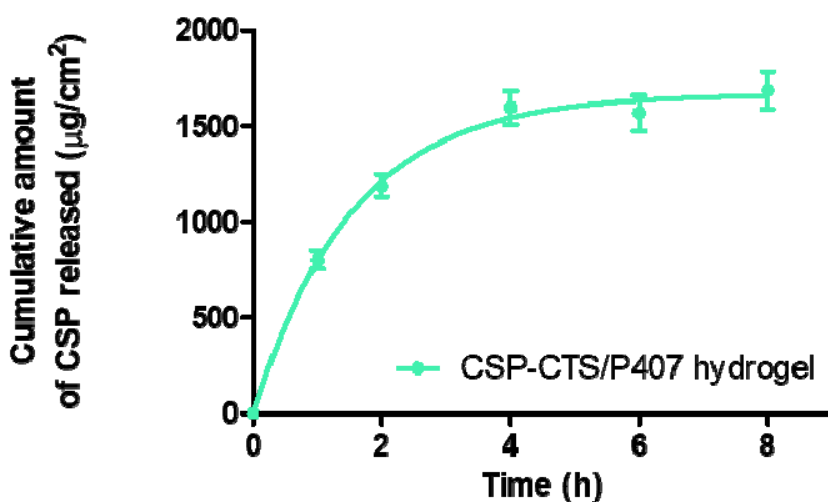

\begin{tabular}{lc}
\hline \multicolumn{2}{c}{ CSP-CTS/P407 hydrogel } \\
\hline \multicolumn{2}{c}{ One phase exponential association } \\
\hline Best-fit values \\
\hline$Y \max (\mu \mathrm{g} / \mathrm{cm} 2)$ & 1667.00 \\
$K(1 / h)$ & 0.65 \\
HalfLife $(h)$ & 1.07 \\
\hline Std. Error & \\
\hline$Y \max$ & 49.39 \\
$K$ & 0.07 \\
$R^{2}$ & 0.97 \\
\hline
\end{tabular}

Figure 6. Cumulative amounts of CSP released from: (A) CSP-CTS hydrogel at $37^{\circ} \mathrm{C}$; (B) CSP-P407 hydrogel at $37^{\circ} \mathrm{C}$; and (C) CSP-CTS/P407 hydrogel at $37^{\circ} \mathrm{C}$. Data represent mean $\pm \mathrm{SD}(n=3)$. 
A

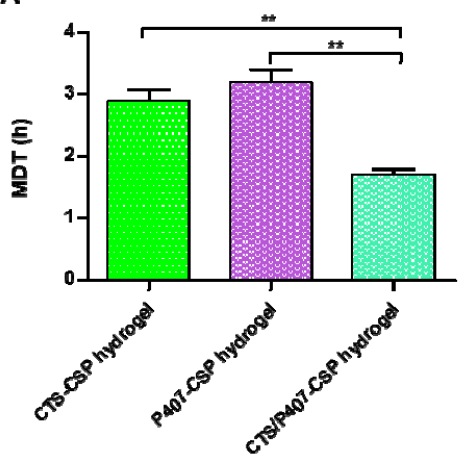

B

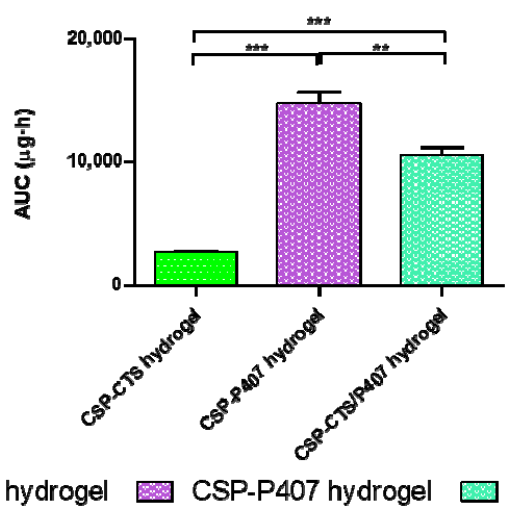

C

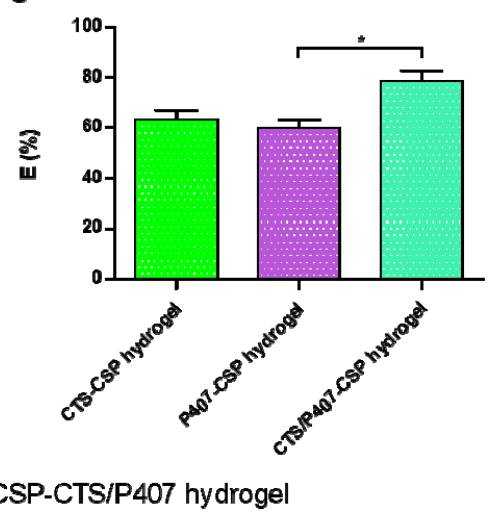

Figure 7. Non-modelistic parameters of: (A) mean dissolution time, MDT; (B) area under the curve, AUC; and (C) efficiency, $\mathrm{E}\left({ }^{*} p<0.05,{ }^{* *} p<0.01,{ }^{* * *} p<0.001\right)$.

Figure 8 illustrates the permeation profiles of CSP hydrogels through vaginal mucosa. The highest permeation profile was found for CSP-CTS hydrogel, followed by CSP-P407, and finally, CSP-CTS/P407. CTS has the capacity to interact with epithelial tight junctions increasing drug penetration [63,71]. Additionally, P407 is a potential enhancer for transmucosal drug delivery [72], due to their surfactant properties [73]. Interestingly, CSP-CTS/P407 hydrogel showed the lowest absorption, and will predictably produce the fewest side effects.

The calculated permeation kinetics parameters and CSP retained amount are reported in Table 4. Taking into account an application surface area of $62.8 \mathrm{~cm}^{2}$ for the vaginal cavity [74], and a plasmatic clearance $\left(\mathrm{Cl}_{p}\right)$ of $0.55 \mathrm{~L} / \mathrm{h}$ [68-70], the theoretical human plasmatic steady-state concentration $\left(\mathrm{Cl}_{s s}\right)$ that CSP would achieve was also calculated, being $1.65 \pm 0.01 \mu \mathrm{g} / \mathrm{mL}, 0.95 \pm 0.22 \mu \mathrm{g} / \mathrm{mL}$ and $1.43 \pm 0.12 \mu \mathrm{g} / \mathrm{mL}$ for CSP-CTS, CSPP407 and CSP-CTS/P407, respectively. Therefore, no systemic side effects related to the use of CSP are expected. Finally, the amount of CSP remaining in the vaginal mucosa for CSP-CTS, CSP-P407 and CSP-CTS/P407, resulted to be $156.23 \mu \mathrm{g} / \mathrm{cm}^{2}, 118.51 \mu \mathrm{g} / \mathrm{cm}^{2}$ and $409.40 \mu \mathrm{g} / \mathrm{cm}^{2}$, respectively.
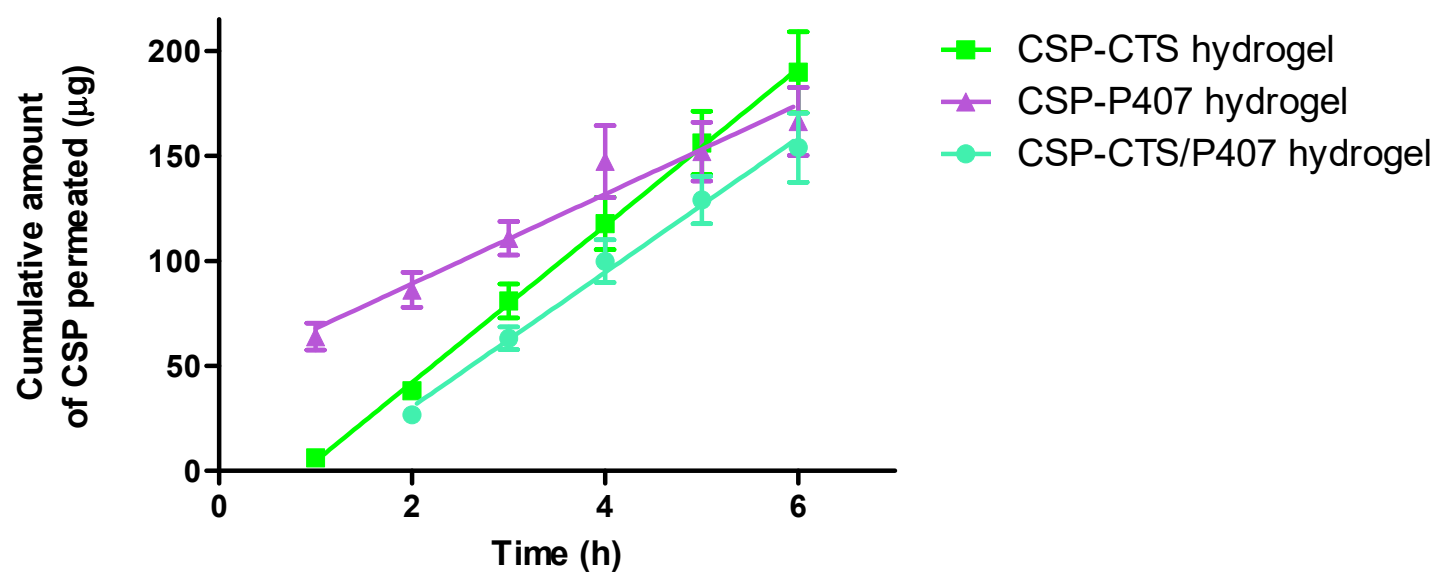

Figure 8. Cumulative amount of CSP permeated $(\mu \mathrm{g})$ through vaginal mucosal upon application of CSP hydrogels. Each value represents the mean $\pm \mathrm{SD}(n=3)$.

To obtain the maximum therapeutic efficacy of the antifungal treatment, the formulation must remain long enough and at high concentration in the vaginal epithelium [75]. Based on the obtained data, the proposed formulation that is able to penetrate and retain significant amounts of CSP in the vaginal mucosa is CSP-CTS/P407 hydrogel. Then this is the best formulation to ensure a local action. 
Table 4. Estimated permeation and retention parameters of CSP hydrogels. Values are reported as the mean $\pm \operatorname{SD}(n=3)$.

\begin{tabular}{|c|c|c|c|c|}
\hline \multirow{2}{*}{$\begin{array}{c}\text { Biopharmaceutical } \\
\text { Parameter }\end{array}$} & \multicolumn{3}{|c|}{ Formulations } & \multirow{2}{*}{$\begin{array}{l}\text { Statistic } \\
p<0.05\end{array}$} \\
\hline & CSP-CTS Hydrogel 1 & CSP-P407 Hydrogel ${ }^{2}$ & CTS/P407 Hydrogel ${ }^{3}$ & \\
\hline $\mathrm{J}(\mu \mathrm{g} / \mathrm{h})$ & $36.76 \pm 0.31$ & $21.08 \pm 4.98$ & $31.84 \pm 2.76$ & $\begin{array}{l}1 \text { vs. } 2 \\
2 \text { vs. } 3\end{array}$ \\
\hline $\mathrm{K}_{\mathrm{p}} \times 10^{4}(\mathrm{~cm} / \mathrm{h})$ & $7.24 \pm 0.06$ & $4.15 \pm 0.98$ & $6.27 \pm 0.54$ & $\begin{array}{l}1 \text { vs. } 2 \\
2 \text { vs. } 3\end{array}$ \\
\hline $\mathrm{C}_{\mathrm{ss}}(\mu \mathrm{g} / \mathrm{mL})$ & $1.65 \pm 0.01$ & $0.95 \pm 0.22$ & $1.43 \pm 0.12$ & $\begin{array}{l}1 \text { vs. } 2 \\
2 \text { vs. } 3\end{array}$ \\
\hline $\mathrm{Q}_{\mathrm{r}}\left(\mu \mathrm{g} / \mathrm{cm}^{2}\right)$ & $156.23 \pm 14.91$ & $118.51 \pm 12.78$ & $409.40 \pm 48.34$ & $\begin{array}{l}1 \text { vs. } 3 \\
2 \text { vs. } 3\end{array}$ \\
\hline
\end{tabular}

\subsection{Histological Evaluation}

The histomorphological analysis of the vaginal mucosa was performed under light microscope. Representative images of assayed treatments are shown in Figure 9. The non-keratinized stratified squamous vaginal epithelium (about 6-7 layers of cells) can be shown in control conditions (Figure 9A). A treatment with ethanol was performed as a positive control to show altered epithelium. The ethanol only induced a contraction of the epithelium. The treatment with CSP-CTS and CSP-CTS/P407 (Figure 9C,D, respectively) conserved the thickness of the epithelium whereas the treatment with CSP-P407 hydrogel (Figure 9E) induced the loss of some of the outermost layers during the processing of the samples.
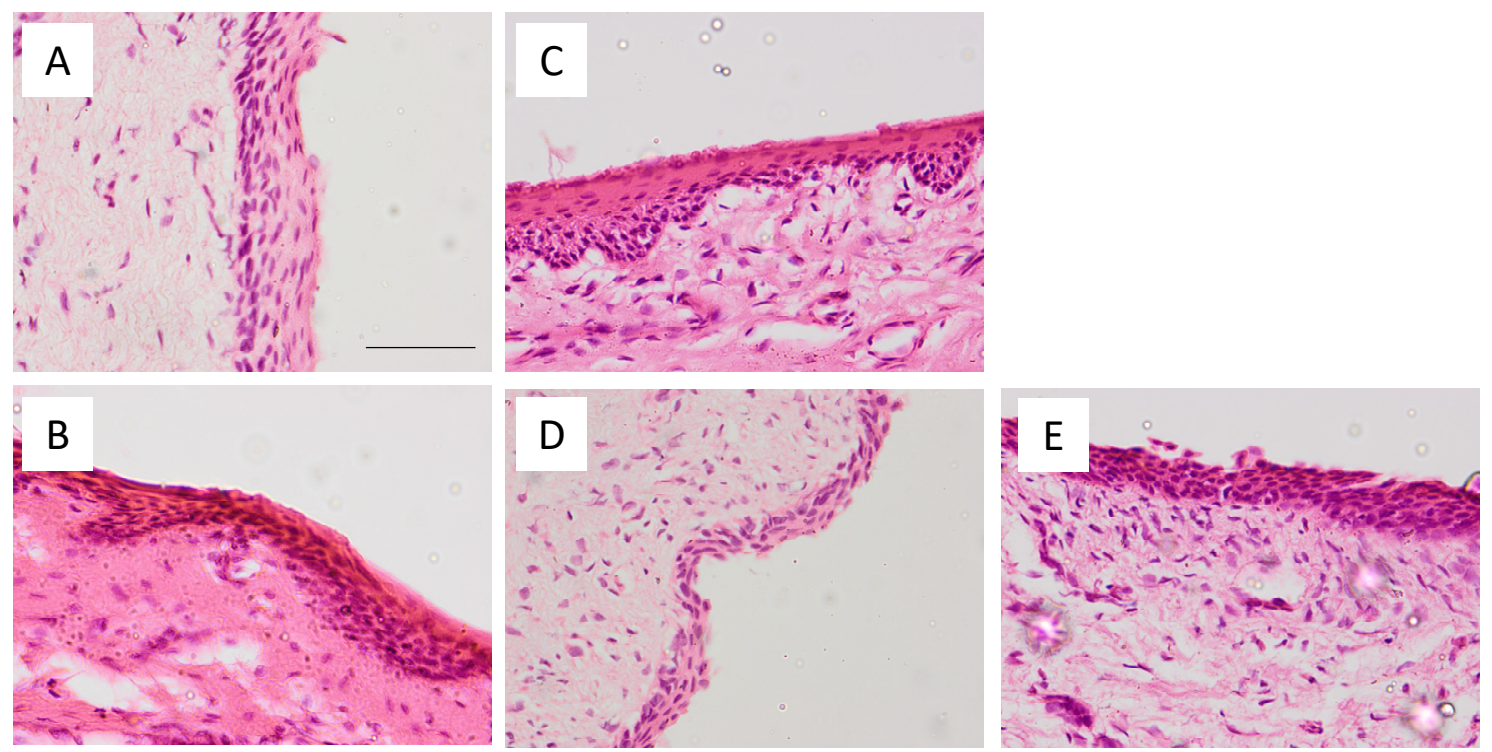

Figure 9. Histological sections of vagina stained with haematoxylin and eosin of: (A) normal vaginal mucosa; (B) damaged vaginal mucosa with ethanol; (C) vaginal mucosa treated with CSP-CTS hydrogel; (D) vaginal mucosa treated with CSP-P407 hydrogel; and (E) vaginal mucosa treated with CSP-CTS/P407 hydrogel. Scale bar $=50 \mu \mathrm{m}$, magnification $=400 \times$.

\subsection{Antifungal Efficacy}

The antimicrobial activity study of the CSP-loaded hydrogels has shown that they are effective on different species of Candida, producing wide areas of inhibition, and demonstrating the effectiveness of these products. Although for C. auris DSM 21092 they strongly inhibit after $24 \mathrm{~h}$ of incubation, a small resistant growth was found in the initial inhibition area at $48 \mathrm{~h}$ and, consequently, they would not be useful to eliminate this strain.

In the case of blank formulations (CTS, P407 and CTS/P407 hydrogels without CSP), it was observed that they prevent the development of studied yeasts at the point where 
samples were applied on the agar plate. These formulations contain CTS, which has been reported to posses antimicrobial activity against a wide range of microorganisms, such as bacteria, fungi, and yeast $[35,76,77]$. The formulations did not allow development at the point of application and did not diffuse into the agar surface as the CSP-loaded hydrogels did. An inhibitory action of CTS on fungal growth was evidenced, but it seems as previously described [78] that it largely depends on the physicochemical characteristics.

The results obtained are summarized in Table 5. CSP-CTS, CSP-P407 and CSPCTS/P407 hydrogels would be useful for the treatment of VVC, as they have been effective in eliminating four of the Candida spp. tested.

Table 5. Antimicrobial activity of CSP-CTS, CSP-P407 and CSP-CTS/P407 hydrogels; and CTS, P407 and CTS/P407 hydrogels.

\begin{tabular}{|c|c|c|c|c|c|}
\hline & \multicolumn{5}{|c|}{ Yeast Tested } \\
\hline & C. albicans ATCC 10231 & $\begin{array}{c}\text { C. auris } \\
\text { DSM } 21092\end{array}$ & C. tropicalis ATCC 7349 & C. glabrata АТСС 66032 & $\begin{array}{l}\text { C. parapsilosis ATCC } \\
22019\end{array}$ \\
\hline \multicolumn{6}{|c|}{ Production of large areas of inhibition } \\
\hline CSP-CTS hydrogel & $+(a)$ & $\mathrm{R}^{\text {(b) }}$ & + & + & + \\
\hline CSP-P407 hydrogel & + & $\mathrm{R}$ & + & + & + \\
\hline $\begin{array}{l}\text { CSP-CTS/P407 } \\
\text { hydrogel }\end{array}$ & + & $\mathrm{R}$ & + & + & + \\
\hline \multicolumn{6}{|c|}{ Inhibition of fungi in situ where the sample has been deposited } \\
\hline CTS hydrogel & $+r^{(c)}$ & $+\mathrm{r}$ & + & + & + \\
\hline P407 hydrogel & + & + & + & + & - \\
\hline CTS/P407 hydrogel & $+\mathrm{r}$ & $+r$ & + & + & + \\
\hline
\end{tabular}

(a) +; formulation totally effective against the strain tested; - formulation does not produce any type of action on yeast growth. (b) $\mathrm{R}$; There is a very marked inhibition effect on yeast growth at $24 \mathrm{~h}$, but when incubating for longer up to $48 \mathrm{~h}$, resistant growth appears within the first inhibition zone. ${ }^{(c)}+,-o+r$; Regarding the antifungal activity of the excipients at the point where the sample has been placed, whether they have inhibited growth, +, or not, - , or inhibit with resistant growth, + r.

\section{Conclusions}

In this work, CSP-loaded hydrogels of CTS, P407 and combination of both have been developed for the first time aimed for the treatment of VVC. All formulations were extensively characterized. The CSP-CTS/P407 hydrogel, formed by the combination of both polymers, proved to be the best formulation for topical administration of CSP against fungal infections. This hydrogel showed better spreadability and extrudability properties than the reference formulation, important factor to evaluate in topical application. It has excellent mucoadhesive properties, essential for formulations destined for vaginal drug administration. In addition, it was shown to be the formulation that retained the highest amount of CSP in the vaginal mucosa, providing the desired local therapeutic effect. It should therefore not cause any systemic side effects. The hydrogel was well tolerated by the vaginal mucosa because no significant mucosal barrier disruption or irritability was observed. These results demonstrate that CSP-CTS/P407 hydrogel is a stable, suitable and safe formulation for the treatment of VVC.

\section{Materials and Methods}

\subsection{Materials}

\subsubsection{Chemical and Reagents}

CSP acetate salt was supplied from SunPharma (Barcelona, Spain). Trifluoroacetic acid, methanol, mucin from porcine stomach type III and medium molecular weight CTS (190-310 KDa molecular weight, $\geq 75 \%$ deacetylated) were purchased from Sigma Aldrich (Madrid, Spain). Pluronic ${ }^{\circledR}$ F-127 (P407) was provided by BASF (Barcelona, Spain). Acetic acid was obtained from Panreac (Barcelona, Spain). Physiological saline $0.9 \%$ was supplied by Grifols Laboratories S.A (Barcelona, Spain). Double distilled water was used after filtration in a Milli-Q ${ }^{\circledR}$ Gradient A10 system apparatus (Millipore Iberica S.A.U.; Madrid, Spain). Commercial formulation of clotrimazole (Gine-Canestén ${ }^{\circledR}, 20 \mathrm{mg} / \mathrm{g}$ ) for vaginal application was obtained from a local pharmacy. Ketamine $\mathrm{HCl}$ was purchased from Pfizer (Madrid, Spain). Xylazine was obtained from Laboratories Calier (Barcelona, Spain). Midazolam, propofol and sodium thiopental were supplied by B. Braun Medicals 
(Barcelona, Spain). Isoflurane was purchased from Baxter (Valencia, Spain). Hank's balanced salt solution (HBSS) (Composition in $\mathrm{g} / \mathrm{L}: \mathrm{CaCl}_{2}=0.14 ; \mathrm{KCl}=0.14 ; \mathrm{KH}_{2} \mathrm{PO}_{4}=0.06$; $\mathrm{MgSO}_{4}=0.1 ; \mathrm{MgCl}_{2}=0.1 ; \mathrm{NaCl}=8.0 ; \mathrm{NaHCO}_{3}=0.35 ; \mathrm{Na}_{2} \mathrm{HPO}_{4}=0.09 ;$ Glucose = 1) was obtained from Biological Industries (Kibbutz Beit Haemek, Israel). Polytetrafluoroethylene (PTFE) membranes were acquired from Pall ${ }^{\circledR}$ Corporation (Madrid, Spain). All other chemicals and reagents used in this study were all of analytical grade.

\subsubsection{Biological Tissue for Ex Vivo Assays}

Vaginal mucosa tissues were obtained from pigs in accordance with protocols prescribed by the Animal Experimentation Ethics Committee of the University of Barcelona, Spain (CEEA-UB) code 10617. Female pigs weighing 20-25 kg, were anesthetized with intramuscular administration of ketamine $\mathrm{HCl}(3 \mathrm{mg} / \mathrm{kg})$, xylazine $(2.5 \mathrm{mg} / \mathrm{kg})$ and midazolam $(0.17 \mathrm{mg} / \mathrm{kg})$. Propofol $(3 \mathrm{mg} / \mathrm{kg})$ was administered via atrial vein after sedation and immediately afterwards they were intubated and maintained under anesthesia inhaled with isoflurane. Finally, three animals were sacrificed under veterinary supervision at the Animal Facility of the Bellvitge Campus of the University of Barcelona (Spain) using an overdose of sodium thiopental. Vaginal mucosa tissues were maintained in HBSS and refrigerated until experiments [79]. Before use, the vaginal mucosa tissues were superficially cleaned with gauze soaked in $0.05 \%$ dodecyl sulphate solution, followed by distilled water.

\subsection{Preparation of CSP Hydrogels}

Firstly, blank CTS hydrogel was prepared by dispersion of appropriate amount of CTS $(2 \%, w / v)$ in $1 \%$ aqueous acetic acid, previously prepared, with continuous stirring until homogenization. Subsequently, CSP loaded CTS hydrogel (CSP-CTS hydrogel) was obtained by solubilization of CSP in blank CTS hydrogel by manual stirring, yielding at $2 \%(w / v)$ hydrogel of CTS and CSP.

CSP loaded P407 hydrogel (CSP-P407 hydrogel) was elaborated as follows; a concentration of 20\% (w/v) P407 and 2\% (w/v) CSP were mixed and stirred overnight at $4{ }^{\circ} \mathrm{C}$.

On the other hand, to prepare CSP loaded CTS/P407 hydrogel (CSP-CTS/P407 hydrogel), an appropriate amount of P407 and CSP was pre-mixed and kept at $4{ }^{\circ} \mathrm{C}$. This mixture was dispersed in a pure CTS hydrogel to reach a final concentration of $2 \%(w / v)$ for CTS and CSP, and 20\% $(w / v)$ for P407. The formation of this hydrogel is represented schematically in Figure 10.

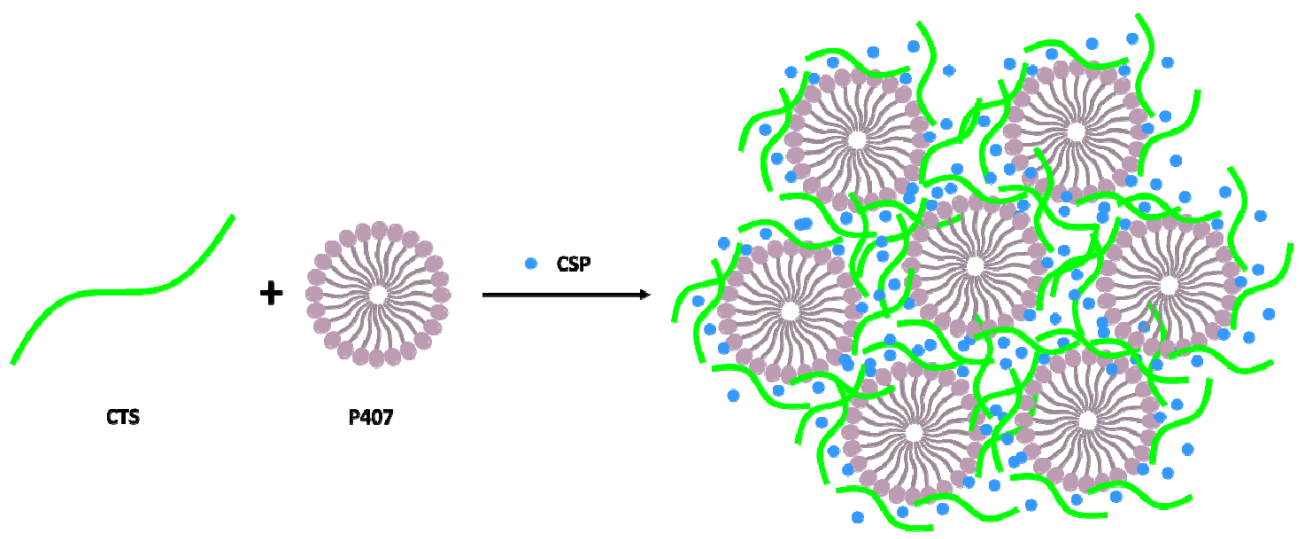

Figure 10. Schematic representation of the formation of the CSP-CTS/P407 hydrogel.

After preparation of hydrogels no insoluble particles were observed. Therefore, all samples were stored at $4{ }^{\circ} \mathrm{C}$. 


\subsection{Physical Characterization of CSP Hydrogels}

\subsection{1. $\mathrm{pH}$ Measurements}

The determination of the $\mathrm{pH}$ values of samples was performed using a digital $\mathrm{pH} / \mathrm{mV}$ meter-pH 200 (Crison Instruments S.A., Barcelona, Spain). Measurements of samples were conducted at $25^{\circ} \mathrm{C}$ with the hydrogel freshly prepared and stored in a refrigerator $\left(4.00 \pm 1.00^{\circ} \mathrm{C}\right)$ two months after preparation. Readings were recorded as the mean \pm standard deviation (SD) of three replicates.

To mimic application conditions, the formulations were mixed with SVF, which was prepared by mixing $\mathrm{NaCl} 3.510 \mathrm{~g}, \mathrm{KOH} 1.400 \mathrm{~g}, \mathrm{Ca}(\mathrm{OH})_{2} 0.220 \mathrm{~g}$, bovine serum albumin $0.018 \mathrm{~g}$, lactic acid $2.000 \mathrm{~g}$, acetic acid $1.000 \mathrm{~g}$, glycerol $0.160 \mathrm{~g}$, urea $0.400 \mathrm{~g}$ and glucose $5.000 \mathrm{~g}$ to $900 \mathrm{~mL}$ of distilled water in a beaker, and stirred until completely dissolved. The $\mathrm{pH}$ of the mixture was then adjusted to 4.5 using $\mathrm{HCl}$, and the final volume was adjusted to $1 \mathrm{~L}[50,80]$.

\subsubsection{Morphological Studies}

To analyze the structure of developed formulations a JEOL JSM-7001F scanning electron microscope (JEOL Ltd., Peabody, MA, USA) was used. The CSP hydrogels were dried for 5 days using a temperature-controlled heater. Once they have dried, a small quantity of each sample was fixed on a double-coated carbon conductive tape and coated with a thin layer of carbon as a conductor agent in an Emitech K950 coater (Quorum Technologies Ltd., Kent, UK). Finally, the samples were observed in high vacuum mode.

\subsubsection{Surface Electrical Properties}

The surface electrical properties were assessed based on the method previously described by Shaarani et al. [53]. The ZP measurements of unloaded and loaded hydrogels were performed at $25 \pm 0.5^{\circ} \mathrm{C}$ using a Zetasizer ${ }^{\circledR} 2000$ (Malvern Instruments Ltd., Worcestershire, UK). Before measuring, the samples were diluted 100 times in double distilled water. Values are reported as the mean \pm SD of nine replicates.

\subsubsection{Rheological Behavior}

The rheological characterization of the samples was performed $24 \mathrm{~h}$ after hydrogels preparation using a Haake RheoStress 1 rheometer connected to a temperature control Thermo Haake Phoenix II + Haake C25P (Thermo Fisher Scientific, Karlsruhe, Germany). It was equipped with a parallel plate-plate geometry set-up including a fixed bottom plate and a Haake PP60Ti movable upper plate (60 $\mathrm{mm}$ diameter) and operated using Haake RheoWin ${ }^{\circledR}$ Job Manager and Data Manager software v. 4.87.

Rotational tests were carried out to determine the viscosity and flow behavior of the formulations. Each sample was equilibrated by placing it between the plate-plate sensor system $\left(0.5 \mathrm{~mm}\right.$ gap) for $5 \mathrm{~min}$ to attain the running temperature $\left(4,25\right.$ and $\left.37^{\circ} \mathrm{C}\right)$. Then, they were submitted to a three steps shear profile program: a ramp-up period $\left(0-50 \mathrm{~s}^{-1}\right)$ for $3 \mathrm{~min}$, constant shear rate period at $50 \mathrm{~s}^{-1}$ for $1 \mathrm{~min}$ and a ramp-down period $\left(50-0 \mathrm{~s}^{-1}\right)$ for $3 \mathrm{~min}$. The data from the flow curves (shear stress $(\tau)$ versus shear rate $(\Upsilon)$ were fitted to different mathematical models (Newton, Bingham, Ostwald-de-Waele, Herschel-Bulkley, Casson and Cross) $[81,82]$. The model that statistically best described the experimental data was selected based on the best correlation coefficient value (r).

The apparent thixotropy was determined by the presence or the absence of a hysteresis loop. Viscosity mean values (Pa.s) were determined at $50 \mathrm{~s}^{-1}$ from the constant share rate period of each viscosity curve (viscosity $(\eta)$ versus shear rate $(\Upsilon)$.

In addition, the thermosensitive gelation process of the CSP-P407 hydrogel was investigated upon temperature sweeping from 10 to $40^{\circ} \mathrm{C}$ under oscillation mode with a fixed frequency of $1 \mathrm{~Hz}$ and a constant stress of $0.5 \mathrm{~Pa}$. Each sample was equilibrated by placing it between the plate-plate system for $5 \mathrm{~min}$ to attain the start temperature of $4{ }^{\circ} \mathrm{C}$. Then the temperature was increased from 10 to $40^{\circ} \mathrm{C}$ at a controlled ramp speed for $2000 \mathrm{~s}$ and the modules $G^{\prime}$ and $G^{\prime \prime}$, as well as complex viscosity $\left(\eta^{*}\right)$ were measured. 
The temperature at which a sharp rise in viscosity was detected (coinciding with the crossover point where $G^{\prime}=G^{\prime \prime}$ ) was recorded as gelation temperature or SOL-GEL temperature transition (TSOL-GEL) [83,84].

\subsubsection{Spreadability Test}

The extensibility test was evaluated for the CSP-CTS, CSP-P407, CSP-CTS/P407 hydrogels using a commercial formulation of clotrimazole, Gine-Canestén ${ }^{\circledR}(20 \mathrm{mg} / \mathrm{g})$ as reference. To evaluate this property, $0.5 \mathrm{~g}$ of each sample was placed within a circle premarked on a glass plate over which a second glass plate was overlapped, as focused as possible, without sliding of the plates. Force was generated onto the upper plate by adding known weights $(5,10,20,30,40,50,100,150$ and $200 \mathrm{~g})$. So, the samples were compressed to uniform thickness. The weights were removed after $60 \mathrm{~s}$ and the area was recorded. The results were expressed in terms of the spreading area as a function of the applied mass according to the following equation:

$$
\mathrm{S}=\mathrm{d}^{2} \times \pi / 4
$$

where $\mathrm{S}$ is the spreading area $\left(\mathrm{cm}^{2}\right)$ resulting from the applied mass $(\mathrm{g})$, and $\mathrm{d}$ is the mean diameter $(\mathrm{cm})$ reached by the sample. Each sample was measured in triplicate for each weight at room temperature.

Finally, the spreadability results were fitted to mathematical equations (Boltzmann, hyperbola one site and hyperbola two sites). The goodness of the fitting was confirmed by $r$ value.

\subsubsection{Extrudability Study}

This test measures the required force to remove the hydrogel from the container. The syringeability of the developed hydrogels was measured in terms of the weight necessary to be applied to remove a known amount of hydrogel from a vaginal applicator (Figure 11).

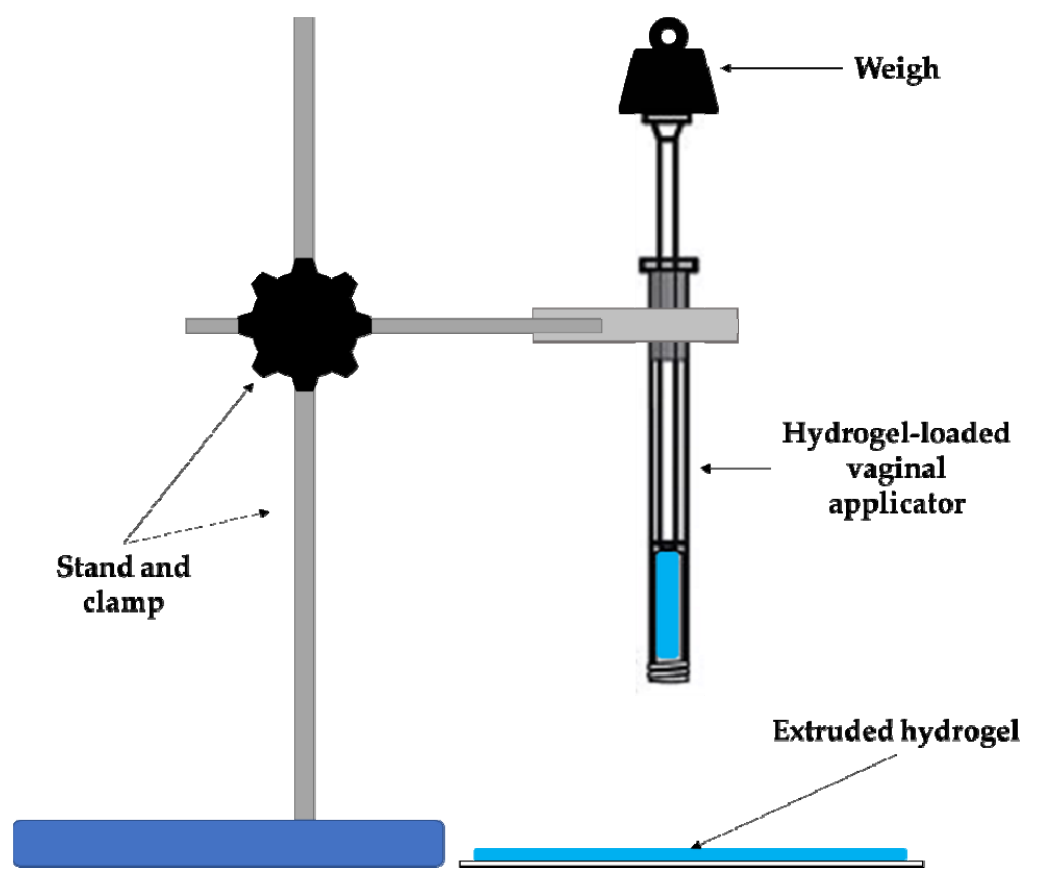

Figure 11. Schematic illustration of the device used for evaluation of spreadability study.

For that purpose $5 \mathrm{~g}$ of each formulation was carefully loaded into vaginal applicators avoiding the formation of air bubbles. The device was vertically placed on a support and known weights were added to its plunge. The plunger was pressed down and the 
extruded weight was recorded. The system was maintained at $4 \pm 0.50{ }^{\circ} \mathrm{C}$, to simulate application conditions.

The syringeability of developed CSP hydrogels was calculated according to the following equation:

$$
\mathrm{E}=\mathrm{W} / \mathrm{A}
$$

where $\mathrm{W}$ is the weigh applied (g) to extrude the sample from the applicator and $\mathrm{A}$ the area $\left(\mathrm{cm}^{2}\right)$ of the extruded hydrogel from the vaginal applicator. The data obtained were expressed as the mean $\pm \mathrm{SD}$ of three replicates.

\subsubsection{Evaluation of Mucoadhesion Properties}

The mucoadhesive property of CSP formulations was evaluated by measuring the influence of the samples on the zeta potential of mucin [85]. Each sample was dispersed with an equivalent amount of porcine mucin solution $1 \%(w / v)$ under continuous stirring. The mixtures of hydrogel-mucin were allowed to equilibrate overnight at room temperature. The surface charge of samples was detected using a Zetasizer ${ }^{\circledR} 2000$ (Malvern Instruments Ltd., Worcestershire, UK). Readings were recorded as the mean \pm SD of nine replicates.

\subsection{In Vitro Release and Kinetic Evaluation}

The in vitro release study of CSP from the hydrogels was performed using amber glass vertical diffusion Franz cells (FDC 400, Crown Glass, Somerville, NY, USA) of $12 \mathrm{~mL}$ volume receiver chamber and $2.54 \mathrm{~cm}^{2}$ effective diffusional area. Polytetrafluoroethylene membranes (wwPTFE $0.45 \mu \mathrm{m} 47 \mathrm{~mm}$ discs) were mounted between the donor and receptor compartment. The receptor fluid consisted of physiological saline $0.9 \%$, which was kept under continuous stirring $(600 \mathrm{rpm})$. The system was maintained at $37 \pm 0.50{ }^{\circ} \mathrm{C}$, to simulate vaginal conditions in vivo.

Drug release studies were carried out by placing a known amount of CSP hydrogels on the donor compartment. Air bubbles under the membranes were removed and the system was allowed to equilibrate for at least $30 \mathrm{~min}$ before samples were applied. To prevent evaporation of the donor compartment and sampling ports, these were sealed with parafilm. At different scheduled times during $8 \mathrm{~h}$, samples of receptor compartment were collected and the same volume was immediately replaced with tempered physiological saline. The collected samples were analyzed for CSP content by Ultra Performance Liquid Chromatography (UPLC) methodology previously validated according to ICH Q2 (R1) guidelines. Values are reported as the mean $\pm \mathrm{SD}$ of three replicates. The data obtained were fitted to various mathematical models (One phase exponential association, Boltzmann sigmoidal, one site binding) to determine the release kinetics. The model was chosen according to the best $\mathrm{r}^{2}$ value.

Furthermore, some amodelistic parameters such as mean dissolution time (MDT), the area under the curve (AUC), and efficiency (E) were also estimated. MDT is the mean dissolution time of the CSP in the formulation along the process. AUC represents the amount of CSP that is released from the formulation and E the efficiency.

\subsection{Ex Vivo Permeation of CSP through Vaginal Mucosa}

The ex vivo drug permeation study of CSP was carried out using amber glass vertical diffusion Franz cells (FDC 400, Crown Glass, Somerville, NY, USA). Porcine vaginal mucosas were used as permeation membranes with the epithelium region facing the donor compartment and the connective region facing the receiver compartment. The receptor compartments were filled with physiological saline $0.9 \%$, which were kept under continuous stirring at $600 \mathrm{rpm}$ and maintained at $37 \pm 0.5^{\circ} \mathrm{C}$. Sink conditions were ensured throughout the study. At different scheduled times samples of receptor compartment were collected via syringe and the same volume was immediately replaced with physiological saline for $6 \mathrm{~h}$. The collected samples were analyzed for drug content by UPLC. Three determinations were made for each sample from the same donor to avoid variability due to membranes. Values are reported as the mean $\pm \mathrm{SD}$. 


\subsubsection{Calculation of the Permeation Parameters}

The cumulative amounts of CSP $(\mu \mathrm{g})$ that had penetrated per unit of vaginal mucosa surface area $\left(\mathrm{cm}^{2}\right)$ were collected and plotted versus time (h). Permeation parameters as flux $(\mathrm{J}, \mu \mathrm{g} / \mathrm{h})$ was calculated by plotting the cumulative amount of permeated drug against time by using the Prism ${ }^{\circledR}$ software v. 5.00 (GraphPad Software Inc., San Diego, CA, USA). The slope of the linear regression was also determined.

The permeability coefficients $\left(\mathrm{K}_{\mathrm{p}}, \mathrm{cm} / \mathrm{h}\right)$ were obtained according to the following equation:

$$
\mathrm{K}_{\mathrm{p}}=\mathrm{J} / \mathrm{C}_{0}
$$

where $C_{0}$ is the initial drug concentration in the donor compartment, 20,000 $\mu \mathrm{g} / \mathrm{mL}$.

The predicted drug steady-state plasma concentration $\left(\mathrm{C}_{\mathrm{ss}}, \mu \mathrm{g} / \mathrm{mL}\right)$ that would penetrate after topical application was calculated using the equation:

$$
\mathrm{C}_{\mathrm{ss}}=\mathrm{J} \times \mathrm{A} / \mathrm{Cl}_{\mathrm{p}}
$$

where $\mathrm{C}_{\mathrm{ss}}$ is the plasma steady-state concentration, $\mathrm{J}$ the flux determined in this study, $\mathrm{A}$ the hypothetical area of application $\left(62.8 \mathrm{~cm}^{2}\right)$ and $\mathrm{Cl}_{\mathrm{p}}$ the plasmatic clearance $(0.55 \mathrm{~L} / \mathrm{h})[68-70]$.

Finally, the data obtained from permeation studies as a function of time were fitted to different mathematical models to determine the kinetics.

\subsubsection{Amount of CSP Retained in the Vaginal Mucosa}

In order to detect differences between formulations, the quantity of CSP remaining on the vaginal mucosal, $\mathrm{Q}_{\mathrm{r}}\left(\mu \mathrm{g} / \mathrm{cm}^{2}\right)$, was also determined. For this, after permeation assays, the residual CSP hydrogel on the vaginal mucosa membranes was removed using a swab. The tissues were taken out of the device and cleaned with gauze soaked in sodium lauryl sulphate $0.05 \%$ and washed with distilled water. The permeation areas of the vaginal mucosa membranes were cut, weighed, perforated with a thin needle and immersed in $2 \mathrm{~mL}$ of physiological saline $0.9 \%$ for $15 \mathrm{~min}$ using an ultrasonic bath. Samples were analyzed by UPLC.

\subsection{Analysis of CSP in Solution}

The UPLC system consisted in an Acquity I CLASS UPLC System (Waters, Milford, CT, USA) coupled to an Acquity TUV and an Acquity Fluorescence Detector. Fluorescence detection was carried out at 224 and $304 \mathrm{~nm}$ for excitation and emission wavelengths, respectively.

The chromatography separation was performed with a Lichrospher RP-8 column $(125 \times 4 \mathrm{~mm}, 5 \mu \mathrm{m}$, Phenomenex). The method had the column at room temperature. The flow rate and the injection volume were $0.8 \mathrm{~mL} / \mathrm{min}$ during $8 \mathrm{~min}$ and $10 \mu \mathrm{L}$, respectively. The mobile phase A consisted of $0.1 \%$ of trifluoroacetic acid (TFA) in Milli- ${ }^{\circledR}$ water and mobile phase $B$ comprised methanol. The gradient elution program was: $50-50 \%$ B for 0-5 $\mathrm{min} ; 100 \%$ B for $5-6 \mathrm{~min} ; 50-50 \% \mathrm{~B}$ for $6-8 \mathrm{~min}$.

\subsection{Histological Evaluation}

The hydrogel formulations were applied for $6 \mathrm{~h}$ to study the vaginal mucosal. Then, the tissue was removed from the Franz cell rinsed with PBS pH 7.4, and set overnight in 4\% buffered formaldehyde and embedded in paraffin wax. Transversal sections $(6 \mu \mathrm{m})$ were stained with hematoxylin and eosin and observed for the evaluation of the histomorphology under a light microscope Olympus BX41 equipped with Olympus XC50 camera (Olympus Co., Tokyo, Japan). Tissues without gel (blank vaginal mucosa) and with ethanol (damaged vaginal mucosa) were used as the control and positive control conditions, respectively.

\subsection{Antifungal Efficacy}

Antifungal activity of developed formulations was tested by using a modification of the Kirby-Bauer disk diffusion test [86]. Basically, the methodology described in the 
Test Protocol [87] was followed without using disk, but using the capacity to diffuse around the place of the agar where product has been deposited. Five strains of Candida were used to study antimicrobial activity: Candida albicans ATCC 10231 (American Type Culture Collection, Manassas, VA, USA), Candida auris DSM 21092 (German collection of Microorganisms and cell cultures $\mathrm{GmbH}$ ), Candida tropicalis ATCC 7349, Candida glabrata ATCC 66032 and Candida parapsilosis ATCC 22019. The yeast strains were first grown aerobically in Mueller-Hinton (MH) medium supplemented with glucose $2 \%$ at $30^{\circ} \mathrm{C}$ for $48 \mathrm{~h}$. The fungi inoculums were prepared by suspending colonies in Ringer's solution to achieve the desired density equivalent to the $0.5 \mathrm{McF}$ arland. MH-glucose $2 \%$ plates were inoculated three times over the entire agar surface with the help of a yeast-soaked swab by streaking action, rotating the plate approximately $60^{\circ}$ each time to ensure an even distribution of the inoculum that result in a confluent lawn of growth.

The following formulations were studied: CSP-CTS, CSP-P407 and CSP-CTS/P407 hydrogels; CTS, P407 and CTS/P407 hydrogels and controls of nystatin $100 \mathrm{UI} / \mathrm{mL}$ and amphotericin B $250 \mu \mathrm{g} / \mathrm{mL}$. About $5 \mu \mathrm{L}$ of these products were placed onto de yeast inoculated $\mathrm{MH}$-glucose $2 \%$ agar. Plates were incubated at $30{ }^{\circ} \mathrm{C}$ during $48 \mathrm{~h}$. The zone of inhibition for growth of yeasts was observed. Formulations CTS, P407 and CTS/P407 hydrogels were also tested in a $\mathrm{MH}$-glucose $2 \%$ medium where $500 \mu \mathrm{g} / \mathrm{mL}$ chloramphenicol was added to avoid possible bacterial contamination on excipients.

\subsection{Statistical Analysis}

Experimental data were statistically evaluated by one-way analysis of variance (ANOVA) using the GraphPad Prism ${ }^{\circledR}$ software v. 5.00 (Graphpad Software Inc., San Diego, CA USA). Differences were considered significant at $p<0.05$ level. To determine the differences between independent groups, Tukey's test was applied, adopting a confidence level of 95\%.

Author Contributions: N.P.-G.: Investigation, methodology, writing—original draft, formal analysis; J.A.M.-M.: investigation, methodology; A.C.C.-C.: conceptualization, investigation, methodology, formal analysis, funding acquisition, supervision; A.N.-R.: investigation, methodology; M.J.R.-L.: investigation, methodology; N.B.-d.F.: investigation, methodology; J.L.S.-R.: investigation, methodology, review \& editing; F.F.-C.: investigation, methodology, review \& editing; B.C.-N.: conceptualization, investigation, methodology, writing—original draft, formal analysis, funding acquisition, supervision. All authors have read and agreed to the published version of the manuscript.

Funding: This research was funded by the Spanish National Research Council (CSIC), project no. 202080E231, and the Agreement with the University of Barcelona and the University of Granada (Official State Gazette 311, on 27 November 2020).

Institutional Review Board Statement: Not applicable.

Informed Consent Statement: Not applicable.

Data Availability Statement: The data presented in this study are available on request from the corresponding author. The data are not publicly available due to they are part of a Doctoral Thesis and it will be available once the Thesis will be published.

Acknowledgments: The authors would like to thank to AG Sanding from animal facility (University of Barcelona) for his valuable help in animal studies, as well as MJM Lopez and E Giannone from the University of Barcelona for their excellent technical support.

Conflicts of Interest: The authors declare no conflict of interest.

\section{References}

1. Sobel, J.D. Vulvovaginal Candidosis. Lancet 2007, 369, 1961-1971. [CrossRef]

2. Pandey, M.; Choudhury, H.; Abdul-Aziz, A.; Bhattamisra, S.K.; Gorain, B.; Carine, T.; Toong, T.W.; Yi, N.J.; Yi, L.W. Promising Drug Delivery Approaches to Treat Microbial Infections in the Vagina: A Recent Update. Polymers 2020, 13, 26. [CrossRef]

3. Albertini, B.; Passerini, N.; Di Sabatino, M.; Vitali, B.; Brigidi, P.; Rodriguez, L. Polymer-Lipid Based Mucoadhesive Microspheres Prepared by Spray-Congealing for the Vaginal Delivery of Econazole Nitrate. Eur. J. Pharm. Sci. 2009, 36, 591-601. [CrossRef] 
4. $\quad$ Balkus, J.E.; Srinivasan, S.; Anzala, O.; Kimani, J.; Andac, C.; Schwebke, J.; Fredricks, D.N.; McClelland, R.S. Impact of Periodic Presumptive Treatment for Bacterial Vaginosis on the Vaginal Microbiome among Women Participating in the Preventing Vaginal Infections Trial. J. Infect. Dis. 2017, 215, 723-731. [CrossRef]

5. Felix, T.C.; de Brito Röder, D.V.D.; dos Santos Pedroso, R. Alternative and Complementary Therapies for Vulvovaginal Candidiasis. Folia Microbiol. 2019, 64, 133-141. [CrossRef]

6. $\quad$ Lopez, J.E.M. Candidiasis (Vulvovaginal). BMJ Clin. Evid. 2015, 2015, 0815.

7. Cain, D.W.; Cidlowski, J.A. After 62 Years of Regulating Immunity, Dexamethasone Meets COVID-19. Nat. Rev. Immunol. 2020, 20, 587-588. [CrossRef]

8. Arastehfar, A.; Carvalho, A.; Nguyen, M.H.; Hedayati, M.T.; Netea, M.G.; Perlin, D.S.; Hoenigl, M. COVID-19-Associated Candidiasis (CAC): An Underestimated Complication in the Absence of Immunological Predispositions? J. Fungi 2020, 6, 211. [CrossRef] [PubMed]

9. Song, G.; Liang, G.; Liu, W. Fungal Co-Infections Associated with Global COVID-19 Pandemic: A Clinical and Diagnostic Perspective from China. Mycopathologia 2020, 185, 599-606. [CrossRef]

10. Cook, M.T.; Brown, M.B. Polymeric Gels for Intravaginal Drug Delivery. J. Control. Release 2018, 270, 145-157. [CrossRef]

11. Pfaller, M.A.; Diekema, D.J. Rare and Emerging Opportunistic Fungal Pathogens: Concern for Resistance beyond Candida Albicans and Aspergillus Fumigatus. J. Clin. Microbiol. 2004, 42, 4419-4431. [CrossRef] [PubMed]

12. Seyedmousavi, S.; Rafati, H.; Ilkit, M.; Tolooe, A.; Hedayati, M.T.; Verweij, P. Systemic Antifungal Agents: Current Status and Projected Future Developments. Methods Mol. Biol. 2017, 1508, 107-139.

13. Chen, S.C.A.; Slavin, M.A.; Sorrell, T.C. Echinocandin Antifungal Drugs in Fungal Infections: A Comparison. Drugs 2011, 71, 11-41. [CrossRef]

14. Denning, D.W. Echinocandin Antifungal Drugs. Lancet 2003, 362, 1142-1151. [CrossRef]

15. Boucher, H.W.; Groll, A.H.; Chiou, C.C.; Walsh, T.J. Newer Systemic Antifungal Agents: Pharmacokinetics, Safety and Efficacy. Drugs 2004, 64, 1997-2020. [CrossRef] [PubMed]

16. Letscher-Bru, V.; Herbrecht, R. Caspofungin: The First Representative of a New Antifungal Class. J. Antimicrob. Chemother. 2003, 51, 513-521. [CrossRef]

17. Deresinski, S.C.; Stevens, D.A. Caspofungin. Clin. Infect. Dis. 2003, 36, 1445-1457.

18. McCormack, P.L.; Perry, C.M. Caspofungin: A Review of Its Use in the Treatment of Fungal Infections. Drugs 2005, 65, 2049-2068. [CrossRef]

19. Vanić, Ž.; Škalko-Basnet, N. Nanopharmaceuticals for Improved Topical Vaginal Therapy: Can They Deliver? Eur. J. Pharm. Sci. 2013, 50, 29-41. [CrossRef] [PubMed]

20. Ziemczonek, P.; Gosecka, M.; Gosecki, M.; Marcinkowska, M.; Janaszewska, A.; Klajnert-Maculewicz, B. Star-Shaped Poly(Furfuryl Glycidyl Ether)-Block-Poly(Glyceryl Glycerol Ether) as an Efficient Agent for the Enhancement of Nifuratel Solubility and for the Formation of Injectable and Self-Healable Hydrogel Platforms for the Gynaecological Therapies. Int. J. Mol. Sci. 2021, $22,8386$. [CrossRef]

21. Grisin, T.; Bories, C.; Bombardi, M.; Loiseau, P.M.; Rouffiac, V.; Solgadi, A.; Mallet, J.M.; Ponchel, G.; Bouchemal, K. Supramolecular Chitosan Micro-Platelets Synergistically Enhance Anti-Candida Albicans Activity of Amphotericin B Using an Immunocompetent Murine Model. Pharm. Res. 2017, 34, 1067-1082. [CrossRef]

22. Ravani, L.; Esposito, E.; Bories, C.; Moal, V.L.L.; Loiseau, P.M.; Djabourov, M.; Cortesi, R.; Bouchemal, K. Clotrimazole-Loaded Nanostructured Lipid Carrier Hydrogels: Thermal Analysis and in Vitro Studies. Int. J. Pharm. 2013, 454, 695-702. [CrossRef]

23. Ci, T.; Yuan, L.; Bao, X.; Hou, Y.; Wu, H.; Sun, H.; Cao, D.; Ke, X. Development and Anti-Candida Evaluation of the Vaginal Delivery System of Amphotericin B Nanosuspension-Loaded Thermogel. J. Drug Target. 2018, 26, 829-839. [CrossRef]

24. de Lima, J.A.; Paines, T.C.; Motta, M.H.; Weber, W.B.; dos Santos, S.S.; Cruz, L.; da Silva, C.B. Novel Pemulen/Pullulan Blended Hydrogel Containing Clotrimazole-Loaded Cationic Nanocapsules: Evaluation of Mucoadhesion and Vaginal Permeation. Mater. Sci. Eng. C 2017, 79, 886-893. [CrossRef]

25. Kenechukwu, F.C.; Attama, A.A.; Ibezim, E.C.; Nnamani, P.O.; Umeyor, C.E.; Uronnachi, E.M.; Gugu, T.H.; Momoh, M.A.; Ofokansi, K.C.; Akpa, P.A. Surface-Modified Mucoadhesive Microgels as a Controlled Release System for Miconazole Nitrate to Improve Localized Treatment of Vulvovaginal Candidiasis. Eur. J. Pharm. Sci. 2018, 111, 358-375. [CrossRef]

26. Gafiţanu, C.A.; Filip, D.; Cernătescu, C.; Ibănescu, C.; Danu, M.; Pâslaru, E.; Rusu, D.; Tuchiluş, C.G.; Macocinschi, D. Formulation and Evaluation of Anise-Based Bioadhesive Vaginal Gels. Biomed. Pharm. 2016, 83, 485-495. [CrossRef]

27. Zimmermann, E.S.; Ferreira, L.M.; Denardi, L.B.; Sari, M.H.M.; Cervi, V.F.; Nogueira, C.W.; Alves, S.H.; Cruz, L. Mucoadhesive Gellan Gum Hydrogel Containing Diphenyl Diselenide-Loaded Nanocapsules Presents Improved Anti-Candida Action in a Mouse Model of Vulvovaginal Candidiasis. Eur. J. Pharm. Sci. 2021, 167, 106011. [CrossRef]

28. Su, J.; Ma, J.; Mo, F.; Yang, X.; Zhang, P.; Zhang, J. Thermosensitive Hydrogels as a Controlled Release System for Alkannin to Improve Localized Treatment of Candida Vaginitis after External Beam Radiotherapy in Vitro and in Vivo. Pathog. Dis. 2019, 77, ftz041. [CrossRef]

29. Arpa, M.D.; Yoltaş, A.; Onay Tarlan, E.; Şenyüz, C.Ş.; Sipahi, H.; Aydın, A.; Üstündağ Okur, N. New Therapeutic System Based on Hydrogels for Vaginal Candidiasis Management: Formulation-Characterization and in Vitro Evaluation Based on Vaginal Irritation and Direct Contact Test. Pharm. Dev. Technol. 2020, 25, 1238-1248. [CrossRef] 
30. Neoh, C.F.; Leung, L.; Misra, A.; Vajpayee, R.B.; Davies, G.E.; Fullinfaw, R.O.; Stewart, K.; Kong, D.C.M. Penetration of Topically Administered 0.5-Percent Caspofungin Eye Drops into Human Aqueous Humor. Antimicrob. Agents Chemother. 2011, 55, 761-1763. [CrossRef]

31. Chatterjee, S.; Hui, P.C. leung. Review of Stimuli-Responsive Polymers in Drug Delivery and Textile Application. Molecules 2019, 24, 2547. [CrossRef]

32. Peak, C.W.; Wilker, J.J.; Schmidt, G. A Review on Tough and Sticky Hydrogels. Colloid Polym. Sci. 2013, 291, 2031-2047. [CrossRef]

33. Islam, M.; Park, T.-E.; Reesor, E.; Cherukula, K.; Hasan, A.; Firdous, J.; Singh, B.; Kang, S.-K.; Choi, Y.-J.; Park, I.-K.; et al. Mucoadhesive Chitosan Derivatives as Novel Drug Carriers. Curr. Pharm. Des. 2015, 21, 4285-4309. [CrossRef]

34. Jiménez-Gómez, C.P.; Cecilia, J.A. Chitosan: A Natural Biopolymer with a Wide and Varied Range of Applications. Molecules 2020, 25, 3981. [CrossRef]

35. Sahariah, P.; Másson, M. Antimicrobial Chitosan and Chitosan Derivatives: A Review of the Structure-Activity Relationship. Biomacromolecules 2017, 18, 3846-3868. [CrossRef]

36. Liu, L.; Gao, Q.; Lu, X.; Zhou, H. In Situ Forming Hydrogels Based on Chitosan for Drug Delivery and Tissue Regeneration. Asian J. Pharm. Sci. 2016, 11, 673-683. [CrossRef]

37. Rizwan, M.; Yahya, R.; Hassan, A.; Yar, M.; Azzahari, A.D.; Selvanathan, V.; Sonsudin, F.; Abouloula, C.N. PH Sensitive Hydrogels in Drug Delivery: Brief History, Properties, Swelling, and Release Mechanism, Material Selection and Applications. Polymers 2017, 9, 137. [CrossRef]

38. Antunes, F.E.; Gentile, L.; Rossi, C.O.; Tavano, L.; Ranieri, G.A. Gels of Pluronic F127 and Nonionic Surfactants from Rheological Characterization to Controlled Drug Permeation. Colloids Surf. B Biointerfaces 2011, 87, 42-48. [CrossRef]

39. Frank, L.A.; Sandri, G.; D'Autilia, F.; Contri, R.V.; Bonferoni, M.C.; Caramella, C.; Frank, A.G.; Pohlmann, A.R.; Guterres, S.S. Chitosan Gel Containing Polymeric Nanocapsules: A New Formulation for Vaginal Drug Delivery. Int. J. Nanomed. 2014, 9,3151-3161.

40. Jalalvandi, E.; Shavandi, A. In Situ-Forming and PH-Responsive Hydrogel Based on Chitosan for Vaginal Delivery of Therapeutic Agents. J. Mater. Sci. Mater. Med. 2018, 29, 158. [CrossRef]

41. Yang, T.T.; Cheng, Y.Z.; Qin, M.; Wang, Y.H.; Yu, H.L.; Wang, A.L.; Zhang, W.F. Thermosensitive Chitosan Hydrogels Containing Polymeric Microspheres for Vaginal Drug Delivery. Biomed. Res. Int. 2017, 2017, 3564060. [CrossRef]

42. Patil, M.V.; Jadhav, R.L.; Shaikh, S.N.; Belhekar, S.N. Formulation and Evaluation Thermoreversible Gel of Antifungal Agent for Treatment of Vaginal Infection. J. Pharm. Res. Int. 2020, 32, 58-66. [CrossRef]

43. Wang, X.; Wang, J.; Wu, W.; Li, H. Vaginal Delivery of Carboplatin-Loaded Thermosensitive Hydrogel to Prevent Local Cervical Cancer Recurrence in Mice. Drug Deliv. 2016, 23, 3544-3551. [CrossRef]

44. Vasile, C.; Pamfil, D.; Stoleru, E.; Baican, M. New Developments in Medical Applications of Hybrid Hydrogels Containing Natural Polymers. Molecules 2020, 25, 1539. [CrossRef]

45. Chen, Y.; Lee, J.H.; Meng, M.; Cui, N.; Dai, C.Y.; Jia, Q.; Lee, E.S.; Jiang, H.B. An Overview on Thermosensitive Oral Gel Based on Poloxamer 407. Materials 2021, 14, 4522. [CrossRef] [PubMed]

46. Malli, S.; Bories, C.; Pradines, B.; Loiseau, P.M.; Ponchel, G.; Bouchemal, K. In Situ Forming Pluronic ${ }^{\circledR}$ F127/Chitosan Hydrogel Limits Metronidazole Transmucosal Absorption. Eur. J. Pharm. Biopharm. 2017, 112, 143-147. [CrossRef]

47. Park, K.M.; Woo Bae, J.; Joung, Y.K.; Shin, J.W.; Park, K.D. Nanoaggregate of Thermosensitive Chitosan-Pluronic for Sustained Release of Hydrophobic Drug. Colloids Surf. B Biointerfaces 2008, 63, 1-6. [CrossRef]

48. Yoo, H.S. Photo-Cross-Linkable and Thermo-Responsive Hydrogels Containing Chitosan and Pluronic for Sustained Release of Human Growth Hormone (HGH). J. Biomater. Sci. Polym. Ed. 2007, 18, 1429-1441. [CrossRef] [PubMed]

49. Argenta, D.F.; Bernardo, B.D.C.; Chamorro, A.F.; Matos, P.R.; Caon, T. Thermosensitive Hydrogels for Vaginal Delivery of Secnidazole as an Approach to Overcome the Systemic Side-Effects of Oral Preparations. Eur. J. Pharm. Sci. 2021, $159,105722$. [CrossRef] [PubMed]

50. Falavigna, M.; Pattacini, M.; Wibel, R.; Sonvico, F.; Škalko-Basnet, N.; Flaten, G.E. The Vaginal-PVPA: A Vaginal MucosaMimicking in Vitro Permeation Tool for Evaluation of Mucoadhesive Formulations. Pharmaceutics 2020, 12, 568. [CrossRef] [PubMed]

51. Chatterjee, S.; Hui, P.C.-L.; Kan, C.-W.; Wang, W. Dual-Responsive (PH/Temperature) Pluronic F-127 Hydrogel Drug Delivery System for Textile-Based Transdermal Therapy. Sci. Rep. 2019, 9, 11658. [CrossRef] [PubMed]

52. Wang, W.Y.; Hui, P.C.L.; Wat, E.; Ng, F.S.F.; Kan, C.W.; Lau, C.B.S.; Leung, P.C. Enhanced Transdermal Permeability via Constructing the Porous Structure of Poloxamer-Based Hydrogel. Polymers 2016, 8, 406. [CrossRef] [PubMed]

53. Shaarani, S.; Hamid, S.S.; Kaus, N.H.M. The Influence of Pluronic F68 and F127 Nanocarrier on Physicochemical Properties, in Vitro Release, and Antiproliferative Activity of Thymoquinone Drug. Pharmacogn. Res. 2017, 9, 12-20.

54. Berenguer, D.; Alcover, M.M.; Sessa, M.; Halbaut, L.; Guillén, C.; Boix-montañés, A.; Fisa, R.; Calpena-campmany, A.C.; Riera, C.; Sosa, L. Topical Amphotericin B Semisolid Dosage Form for Cutaneous Leishmaniasis: Physicochemical Characterization, Ex Vivo Skin Permeation and Biological Activity. Pharmaceutics 2020, 12, 149. [CrossRef] [PubMed]

55. Chejara, D.R.; Kondaveeti, S.; Prasad, K.; Siddhanta, A.K. Studies on the Structure-Property Relationship of Sodium Alginate Based Thixotropic Hydrogels. RSC Adv. 2013, 3, 15744-15751. [CrossRef]

56. Liu, Y.; Yang, F.; Feng, L.; Yang, L.; Chen, L.; Wei, G.; Lu, W. In Vivo Retention of Poloxamer-Based in Situ Hydrogels for Vaginal Application in Mouse and Rat Models. Acta Pharm. Sin. B 2017, 7, 502-509. [CrossRef] 
57. Sanz, R.; Clares, B.; Mallandrich, M.; Suñer-Carbó, J.; Montes, M.J.; Calpena, A.C. Development of a Mucoadhesive Delivery System for Control Release of Doxepin with Application in Vaginal Pain Relief Associated with Gynecological Surgery. Int. J. Pharm. 2018, 535, 393-401. [CrossRef] [PubMed]

58. Acosta, N.; Sánchez, E.; Calderón, L.; Cordoba-Diaz, M.; Cordoba-Diaz, D.; Dom, S.; Heras, A. Physical Stability Studies of Semi-Solid Formulations from Natural Compounds Loaded with Chitosan Microspheres. Mar. Drugs 2015, 13, 5901-5919. [CrossRef]

59. Giuliano, E.; Paolino, D.; Fresta, M.; Cosco, D. Mucosal Applications of Poloxamer 407-Based Hydrogels: An Overview. Pharmaceutics 2018, 10, 159. [CrossRef] [PubMed]

60. Bansal, M.; Mittal, N.; Yadav, S.K.; Khan, G.; Gupta, P.; Mishra, B.; Nath, G. Periodontal Thermoresponsive, Mucoadhesive Dual Antimicrobial Loaded in-Situ Gel for the Treatment of Periodontal Disease: Preparation, in-Vitro Characterization and Antimicrobial Study. J. Oral Biol. Craniofacial Res. 2018, 8, 126-133. [CrossRef]

61. Desai, P.R.; Jain, N.J.; Sharma, R.K.; Bahadur, P. Effect of Additives on the Micellization of PEO/PPO/PEO Block Copolymer F127 in Aqueous Solution. Colloids Surfaces A Physicochem. Eng. Asp. 2001, 178, 57-69. [CrossRef]

62. Brugués, A.P.; Naveros, B.C.; Campmany, A.C.C.; Pastor, P.H.; Saladrigas, R.F.; Lizandra, C.R. Developing Cutaneous Applications of Paromomycin Entrapped in Stimuli-Sensitive Block Copolymer Nanogel Dispersions. Nanomedicine 2015, 10, 227-240. [CrossRef]

63. Gosecka, M.; Gosecki, M. Antimicrobial Polymer-Based Hydrogels for the Intravaginal Therapies-Engineering Considerations. Pharmaceutics 2021, 13, 1393. [CrossRef] [PubMed]

64. Takeuchi, H.; Thongborisute, J.; Matsui, Y.; Sugihara, H.; Yamamoto, H.; Kawashima, Y. Novel Mucoadhesion Tests for Polymers and Polymer-Coated Particles to Design Optimal Mucoadhesive Drug Delivery Systems. Adv. Drug Deliv. Rev. 2005, 57, 1583-1594. [CrossRef]

65. Saikia, C.; Gogoi, P. Chitosan: A Promising Biopolymer in Drug Delivery Applications. J. Mol. Genet. Med. 2015, s4, 899-910. [CrossRef]

66. Domínguez-Delgado, C.L.; Fuentes-Prado, E.; Escobar-Chávez, J.J.; Vidal-Romero, G.; Rodríguez-Cruz, I.M.; Díaz-Torres, R. Chitosan and Pluronic ${ }^{\circledR}$ F-127: Pharmaceutical Applications. Encycl. Biomed. Polym. Polym. Biomater. 2016, $2016,1513-1535$.

67. Zhou, Y.; Cheng, L.; Lei, Y.L.; Ren, B.; Zhou, X. The Interactions Between Candida Albicans and Mucosal Immunity. Front. Microbiol. 2021, 12, 652725. [CrossRef]

68. Muilwijk, E.W.; Schouten, J.A.; van Leeuwen, H.J.; van Zanten, A.R.H.; de Lange, D.W.; Colbers, A.; Verweij, P.E.; Burger, D.M.; Pickkers, P.; Brüggemann, R.J.M. Pharmacokinetics of Caspofungin in ICU Patients. J. Antimicrob. Chemother. 2014, 69, 3294-3299. [CrossRef] [PubMed]

69. Moor, A.B.-D.; Sysiak-Sławecka, J.; Rypulak, E.; Borys, M.; Piwowarczyk, P.; Raszewski, G.; Onichimowski, D.; Czuczwar, M.; Wiczling, P. Nonstationary Pharmacokinetics of Caspofungin in ICU Patients. Antimicrob. Agents Chemother. 2020, 64, e00345-20.

70. Gustot, T.; Heine, R.T.; Brauns, E.; Cotton, F.; Jacobs, F.; Brüggemann, R.J. Caspofungin Dosage Adjustments Are Not Required for Patients with Child-Pugh B or C Cirrhosis. J. Antimicrob. Chemother. 2018, 73, 2493-2496. [CrossRef] [PubMed]

71. Dodane, V.; Khan, M.A.; Merwin, J.R. Effect of Chitosan on Epithelial Permeability and Structure. Int. J. Pharm. 1999, 182, 21-32. [CrossRef]

72. Dumortier, G.; Grossiord, J.L.; Agnely, F.; Chaumeil, J.C. A Review of Poloxamer 407 Pharmaceutical and Pharmacological Characteristics. Pharm. Res. 2006, 23, 2709-2728. [CrossRef] [PubMed]

73. Bodratti, A.M.; Alexandridis, P. Formulation of Poloxamers for Drug Delivery. J. Funct. Biomater. 2018, 9, 11. [CrossRef] [PubMed]

74. Katz, D.F.; Yuan, A.; Gao, Y. Vaginal Drug Distribution Modeling. Adv. Drug Deliv. Rev. 2015, 92, 2-13. [CrossRef] [PubMed]

75. Ensign, L.M.; Tang, B.C.; Wang, Y.Y.; Tse, T.A.; Hoen, T.; Cone, R.; Hanes, J. Mucus-Penetrating Nanoparticles for Vaginal Drug Delivery Protect against Herpes Simplex Virus. Sci. Transl. Med. 2012, 4, 138ra79. [CrossRef]

76. Raafat, D.; Sahl, H.G. Chitosan and Its Antimicrobial Potential-a Critical Literature Survey. Microb. Biotechnol. 2009 , 2, 186-201. [CrossRef] [PubMed]

77. Raafat, D.; Von Bargen, K.; Haas, A.; Sahl, H.G. Insights into the Mode of Action of Chitosan as an Antibacterial Compound. Appl. Environ. Microbiol. 2008, 74, 3764-3773. [CrossRef]

78. Abilova, G.K.; Kaldybekov, D.B.; Irmukhametova, G.S.; Kazybayeva, D.S.; Iskakbayeva, Z.A.; Kudaibergenov, S.E.; Khutoryanskiy, V.V. Chitosan/Poly(2-Ethyl-2-Oxazoline) Films with Ciprofloxacin for Application in Vaginal Drug Delivery. Materials 2020, 13, 1709. [CrossRef] [PubMed]

79. Amores, S.; Domenech, J.; Colom, H.; Calpena, A.C.; Clares, B.; Gimeno, Á.; Lauroba, J. An Improved Cryopreservation Method for Porcine Buccal Mucosa in Ex Vivo Drug Permeation Studies Using Franz Diffusion Cells. Eur. J. Pharm. Sci. 2014, 60, 49-54. [CrossRef] [PubMed]

80. Aka-Any-Grah, A.; Bouchemal, K.; Koffi, A.; Agnely, F.; Zhang, M.; Djabourov, M.; Ponchel, G. Formulation of Mucoadhesive Vaginal Hydrogels Insensitive to Dilution with Vaginal Fluids. Eur. J. Pharm. Biopharm. 2010, 76, 296-303. [CrossRef]

81. Schramm, G.; Electron, T. A Practical Approach to Rheology and Rheometry. In Thermo Haake, Karlsruhe, 2nd ed.; Gebrueder HAAKE GmbH: Karlsruhe, Germany, 2004.

82. El Moussaoui, S.; Fernández-Campos, F.; Alonso, C.; Limón, D.; Halbaut, L.; Garduño-Ramirez, M.L.; Calpena, A.C.; Mallandrich, M. Topical Mucoadhesive Alginate-Based Hydrogel Loading Ketorolac for Pain Management after Pharmacotherapy, Ablation, or Surgical Removal in Condyloma Acuminata. Gels 2021, 7, 8. [CrossRef] 
83. Soriano-Ruiz, J.L.; Calpena-Campmany, A.C.; Silva-Abreu, M.; Halbout-Bellowa, L.; Bozal-de Febrer, N.; Rodríguez-Lagunas, M.J.; Clares-Naveros, B. Design and Evaluation of a Multifunctional Thermosensitive Poloxamer-Chitosan-Hyaluronic Acid Gel for the Treatment of Skin Burns. Int. J. Biol. Macromol. 2020, 142, 412-422. [CrossRef] [PubMed]

84. Gonzalez-Pizarro, R.; Carvajal-Vidal, P.; Bellowa, L.H.; Calpena, A.C.; Espina, M.; García, M.L. In-Situ Forming Gels Containing Fluorometholone-Loaded Polymeric Nanoparticles for Ocular Inflammatory Conditions. Colloids Surf. B Biointerfaces 2019, 175, 365-374. [CrossRef]

85. Abdellatif, M.M.; Khalil, I.A.; Elakkad, Y.E.; Eliwa, H.A.; Samir, T.M.; Al-Mokaddem, A.K. Formulation and Characterization of Sertaconazole Nitrate Mucoadhesive Liposomes for Vaginal Candidiasis. Int. J. Nanomed. 2020, 15, 4079-4090. [CrossRef]

86. Bauer, A.W.; Kirby, W.M.; Sherris, J.C.; Turck, M. Antibiotic Susceptibility Testing by a Standardized Single Disk Method. Am. J. Clin. Pathol. 1966, 45, 493-496. [CrossRef] [PubMed]

87. Clinical and Laboratory Standard Institute. Performance Standards for Antimicrobial Disk Susceptibility Tests, 11th ed. CLSI Publication Document M02-A11. 2012, Volume 32. Available online: https://www.nih.org.pk/wp-content/uploads/2021/02/ CLSI-2020.pdf (accessed on 12 December 2021). 